\title{
Psychophysical and neuroimaging responses to moving stimuli in a patient with the Riddoch phenomenon due to bilateral visual cortex lesions
}

Citation for published version (APA):

Arcaro, M. J., Thaler, L., Quinlan, D. J., Monaco, S., Khan, S., Valyear, K. F., Goebel, R., Dutton, G. N., Goodale, M. A., Kastner, S., \& Culham, J. C. (2019). Psychophysical and neuroimaging responses to moving stimuli in a patient with the Riddoch phenomenon due to bilateral visual cortex lesions.

Neuropsychologia, 128, 150-165. https://doi.org/10.1016/j.neuropsychologia.2018.05.008

Document status and date:

Published: 01/05/2019

DOI:

10.1016/j.neuropsychologia.2018.05.008

Document Version:

Publisher's PDF, also known as Version of record

Document license:

Taverne

Please check the document version of this publication:

- A submitted manuscript is the version of the article upon submission and before peer-review. There can be important differences between the submitted version and the official published version of record.

People interested in the research are advised to contact the author for the final version of the publication, or visit the DOI to the publisher's website.

- The final author version and the galley proof are versions of the publication after peer review.

- The final published version features the final layout of the paper including the volume, issue and page numbers.

Link to publication

\footnotetext{
General rights rights.

- You may freely distribute the URL identifying the publication in the public portal. please follow below link for the End User Agreement:

www.umlib.nl/taverne-license

Take down policy

If you believe that this document breaches copyright please contact us at:

repository@maastrichtuniversity.nl

providing details and we will investigate your claim.
}

Copyright and moral rights for the publications made accessible in the public portal are retained by the authors and/or other copyright owners and it is a condition of accessing publications that users recognise and abide by the legal requirements associated with these

- Users may download and print one copy of any publication from the public portal for the purpose of private study or research.

- You may not further distribute the material or use it for any profit-making activity or commercial gain

If the publication is distributed under the terms of Article $25 \mathrm{fa}$ of the Dutch Copyright Act, indicated by the "Taverne" license above, 


\title{
Psychophysical and neuroimaging responses to moving stimuli in a patient with the Riddoch phenomenon due to bilateral visual cortex lesions
}

\author{
Michael J. Arcaro ${ }^{\mathrm{a}, \mathrm{b}, \mathrm{c}}$, Lore Thaler ${ }^{\mathrm{d}}$, Derek J. Quinlan ${ }^{\mathrm{e}}$, Simona Monaco ${ }^{\mathrm{f}}$, Sarah Khan $^{\mathrm{g}}$, \\ Kenneth F. Valyear ${ }^{\mathrm{h}}$, Rainer Goebel ${ }^{\mathrm{i}}$, Gordon N. Dutton ${ }^{\mathrm{j}}$, Melvyn A. Goodale ${ }^{\mathrm{e}, \mathrm{g}}$, Sabine Kastner ${ }^{\mathrm{b}, \mathrm{c}}$,
} Jody C. Culham ${ }^{\mathrm{e}, \mathrm{g}, *}$

a Department of Neurobiology, Harvard Medical School, Boston, MA, USA

${ }^{\mathrm{b}}$ Department of Psychology, Princeton University, Princeton, NJ, USA

${ }^{\mathrm{c}}$ Princeton Neuroscience Institute, Princeton, NJ, USA

d Department of Psychology, Durham University, Durham, UK

${ }^{\mathrm{e}}$ Brain and Mind Institute, University of Western Ontario, London, Ontario, Canada

${ }^{\mathrm{f}}$ Center for Mind and Brain Sciences, University of Trento, Trento, Italy

${ }^{g}$ Department of Psychology, University of Western Ontario, London, Ontario, Canada

${ }^{\mathrm{h}}$ School of Psychology, University of Bangor, Bangor, Wales

${ }^{\mathrm{i}}$ Department of Cognitive Neuroscience, Maastricht University, Maastricht, The Netherlands

${ }^{\mathrm{j}}$ Department of Visual Science, Glasgow Caledonian University, Glasgow, UK

A R T I C L E I N F O

\section{Keywords:}

Riddoch phenomenon

Blindsight

Vision

Motion perception

FMRI

Middle temporal area (MT +)

\begin{abstract}
A B S T R A C T
Patients with injury to early visual cortex or its inputs can display the Riddoch phenomenon: preserved awareness for moving but not stationary stimuli. We provide a detailed case report of a patient with the Riddoch phenomenon, MC. MC has extensive bilateral lesions to occipitotemporal cortex that include most early visual cortex and complete blindness in visual field perimetry testing with static targets. Nevertheless, she shows a remarkably robust preserved ability to perceive motion, enabling her to navigate through cluttered environments and perform actions like catching moving balls. Comparisons of MC's structural magnetic resonance imaging (MRI) data to a probabilistic atlas based on controls reveals that MC's lesions encompass the posterior, lateral, and ventral early visual cortex bilaterally (V1, V2, V3A/B, LO1/2, TO1/2, hV4 and VO1 in both hemispheres) as well as more extensive damage to right parietal (inferior parietal lobule) and left ventral occipitotemporal cortex (VO1, PHC1/2). She shows some sparing of anterior occipital cortex, which may account for her ability to see moving targets beyond $\sim 15$ degrees eccentricity during perimetry. Most strikingly, functional and structural MRI revealed robust and reliable spared functionality of the middle temporal motion complex $(\mathrm{MT}+)$ bilaterally. Moreover, consistent with her preserved ability to discriminate motion direction in psychophysical testing, MC also shows direction-selective adaptation in MT +. A variety of tests did not enable us to discern whether input to MT + was driven by her spared anterior occipital cortex or subcortical inputs. Nevertheless, MC shows rich motion perception despite profoundly impaired static and form vision, combined with clear preservation of activation in MT + , thus supporting the role of $\mathrm{MT}+$ in the Riddoch phenomenon.
\end{abstract}

\section{Introduction}

In 1917, a Scottish neurologist, George Riddoch, described a phenomenon whereby five patients with occipital lobe injury, reported seeing moving targets in the affected parts of the visual field even though they could not see stationary targets. Although such patients could perceive "something" moving, the items lacked form and were often described as "vague and shadowy" (Riddoch, 1917). More generally, detection of moving but not static targets, sometimes called statokinetic dissociation (SKD), has even been reported in neurologically intact individuals (Hudson and Wild, 1992; Safran and Glaser, 1980) but may be eliminated with careful methodology (Phu et al., 2016); as such, the term Riddoch phenomenon is typically applied to patients, while SKD can include typical individuals. Historically, a related phenomenon of "blindsight" described patients with damage to visual cortex or its inputs, who could respond correctly to stimuli in their blind fields of which they were unaware (Weiskrantz et al., 1974). However, more recent accounts and taxonomies of blindsight

\footnotetext{
* Corresponding author at: Brain and Mind Institute, University of Western Ontario, London, Ontario, Canada.

E-mail address: jculham@uwo.ca (J.C. Culham).
} 
acknowledge subtypes that may include awareness (Kentridge and Heywood, 1999). Since Riddoch's seminal report, additional patients have been reported showing the Riddoch phenomenon and have been studied in terms of their perceptual reports (Schoenfeld et al., 2002; Zappia et al., 1971) and in some cases, brain function (Stoerig et al., 1998; Zeki and Ffytche, 1998). In addition, later research has also revealed a syndrome with the inverse dissociation to the Riddoch phenomenon, akinetopsia, in which a patient was able to see static images but not perceive their movement (Zihl et al., 1983; Zihl et al., 1991).

Multiple accounts have been given for the Riddoch phenomenon (and blindsight more generally). Most interestingly, the phenomenon can be explained by the combination of damage to the primary visual pathway (from retina to lateral geniculate nucleus, LGN, of the thalamus, to primary (striate) visual cortex, V1) and a sparing of alternate pathways from subcortical structures (including the LGN, pulvinar, and superior colliculus) to extrastriate cortex (reviewed in Ajina and Bridge, 2016). One extrastriate area that appears critical is the middle temporal motion complex, MT + (defined in humans based on the homology with macaque area MT and its satellites; also called V5(+); Tootell et al., 1995; Zeki et al., 1991), which provides output to areas within the dorsal visual stream to guide actions (Milner and Goodale, 1995). Subcortically, the LGN appears to be necessary for the preservation of visual responses in adult extrastriate cortex. Visually evoked responses are detectable in extrastriate cortex of adult monkeys with a lesioned V1 (Collins et al., 2005; Schmid et al., 2013), but are extinguished by inactivation of the LGN (Schmid et al., 2010). Additional subcorticalcortical pathways may also be sufficient for the preservation of cortical visual function in the absence of V1 (Ajina and Bridge, 2018; Mikellidou et al., 2017a) A retina-pulvino-MT pathway can also support residual visual function in cortex following lesions to V1 early in life (Warner et al., 2015). Collicular input to MT via the pulvinar may also support visual function that bypasses V1 (Berman and Wurtz, 2010; Rodman et al., 1990). An alternate account suggests that spared visual function can arise from spared "islands" of occipital tissue (Fendrich et al., 1992); however, at least in some patients, this account is untenable (Kentridge et al., 1997).

Neuroimaging investigations of specific patients with blindsight have provided support for the proposal of alternate subcortical pathways to MT + and beyond. One patient, GY, who demonstrates the Riddoch phenomenon (and blindsight), has been extensively studied with psychophysical testing and neuroimaging. Functional magnetic resonance imaging (fMRI) has shown that two patients, FS (Stoerig et al., 1998) and GY (Zeki and Ffytche, 1998) show spared activation in MT + despite an absence of activation in V1 (ruling out spared islands of processing). In GY, this activation was enhanced for fast motion and trials during which he was aware of the movement (Zeki and Ffytche, 1998). Another patient studied with magnetoencepahalography (MEG) showed responses in MT + that preceded other extrastriate responses (Schoenfeld et al., 2002), consistent with rapid subcortical inputs. The signature of MT + activation had been suggested as a possible means to distinguish genuine blindsight from its absence (including cases arising from confounds; Danckert and Culham, 2010); however, results have been mixed. Some reports show activation in MT + and intact LGNMT + connections (Ajina et al., 2015b) or collicular-extrastriate connections (Leh et al., 2006) in patients with visual-field loss who demonstrate blindsight (including GY; Bridge et al., 2008) but not those who do not. In contrast, another report shows multiple patients with unilateral occipital damage and spared processing within and inputs to ipsilesional MT + , but without behavioral signatures of blindsight or the Riddoch phenomenon (Barleben et al., 2015).

Some have argued that although patients with the Riddoch phenomenon can detect stimulus motion, under some circumstances, they cannot discriminate motion direction (Azzopardi and Cowey, 2001; Barton and Sharpe, 1997). Specifically, three patients with visual field scotomata arising from occipital damage were able to detect a variety of moving stimuli. However, they were able to discriminate direction for

A.
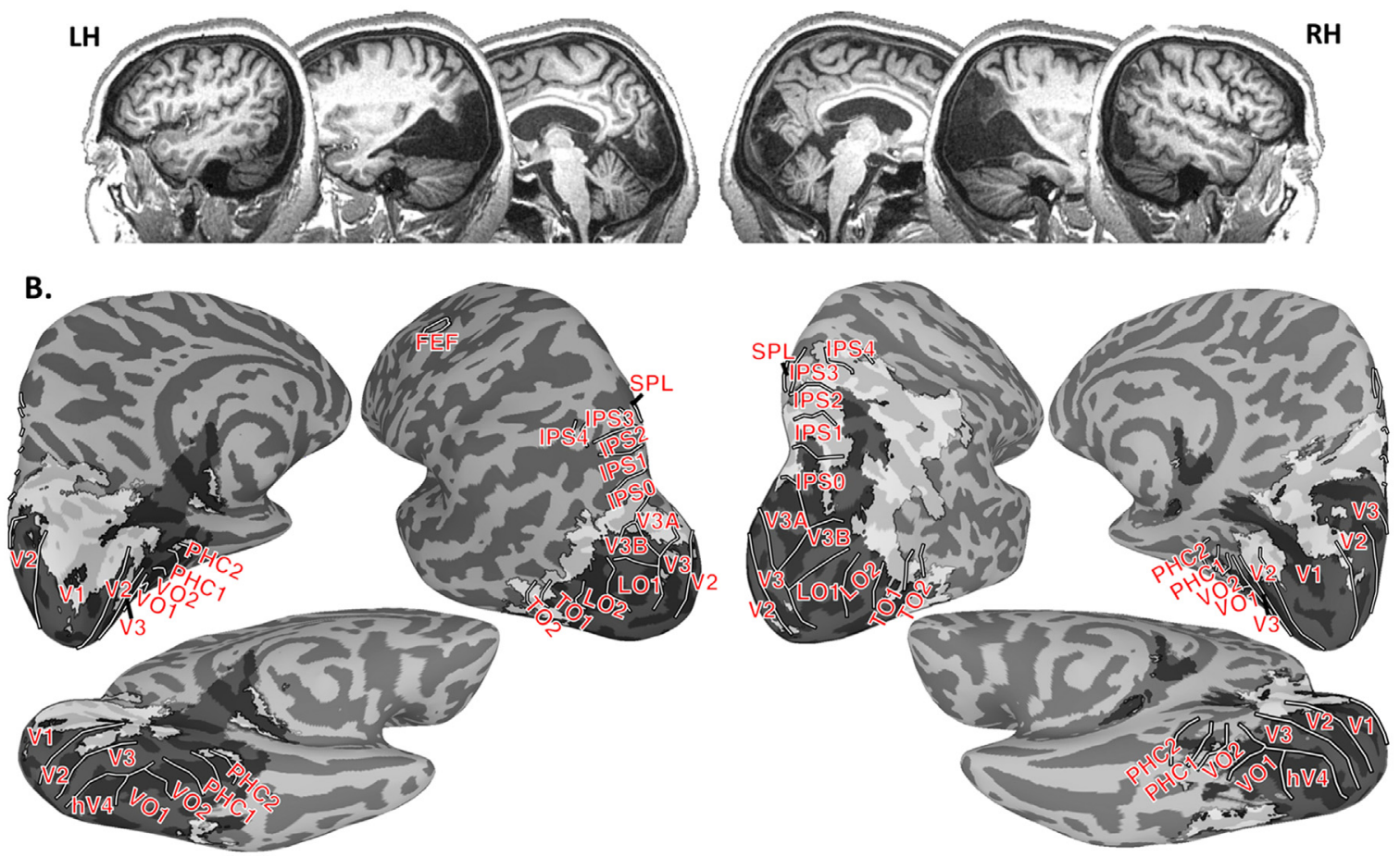

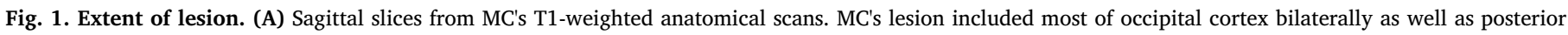

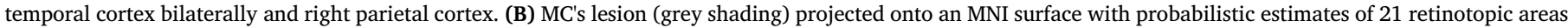

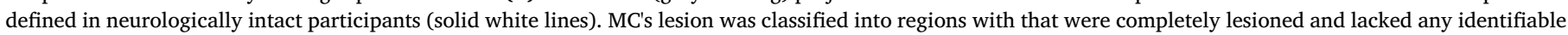

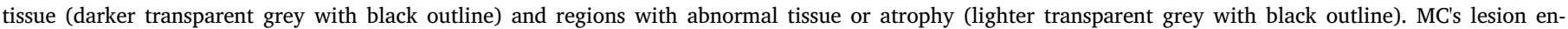
compassed early visual areas V1-V3 as well as extrastriate areas hV4, V3A, V3B, LO1-2, and VO1. 
simple stimuli (single dots or bars), seemingly based on first-order motion processing rather than feature tracking (Azzopardi and Hock, 2011), but not for more complicated patterns (gratings, plaids or random dot kinematograms, RDKs). Patients were also unable to distinguish between incoherent (random) and fully (100\%) coherent motion of RDKs. Moreover, the relationship between RDK coherence and MT + activation to RDKs in the blind fields of patients is abnormal compared to their sighted fields or to controls, suggesting that in the intact brain, V1 input shapes the response to coherence (Ajina et al., 2015a).

In sum, although there are several well-described cases of the Riddoch phenomenon and neuroimaging evidence supports the sparing of motion processing via subcortical inputs to MT + and beyond, many uncertainties remain. The number of cases in the literature is small and, in the most well-studied case of GY, the acquisition of his occipital lesion in childhood has led to concerns that the possibility of extensive plasticity during development makes his case atypical. Moreover, while psychophysical (e.g., Azzopardi and Cowey, 2001) and neuroimaging (e.g., Zeki and Ffytche, 1998) studies of GY have shown detection and neural responses to moving stimuli, our understanding would benefit from further study and additional cases.

Here we provide the first detailed report of a new patient who shows a clear case of the Riddoch phenomenon despite extensive bilateral occipitotemporal lesions resulting from strokes. MC's verbal descriptions of her perceptual experience are striking. For example, she describes seeing rain moving down a window pane but cannot see the stationary objects that would normally be visible through the window. Her case is also striking in terms of the size of her lesions, which extend well beyond the V1 lesions reported in most previous cases of the Riddoch phenomenon (but see de Gelder et al., 2008 for a similar case with comparably extensive lesions). Despite the absence of almost all occipital cortex, MC's visual experiences are surprisingly rich, enabling her not just to perceive moving stimuli, but to use her sense of motion for everyday actions such as navigation and grasping.

Our goals here are twofold. First, we begin by providing a comprehensive case history of MC and detailed description of her structural anatomy, including comparisons with probabilistic databases of visual areas based on data from typical participants. The case details serve as a foundation for our second but more central goal, to use fMRI and psychophysics to investigate MC's preserved motion perception and its neural substrates. The comprehensive case details can also provide a foundation for ongoing and future studies of her abilities and interesting dissociations such as spared grasping of objects despite impaired object perception (Goodale et al., 2008).

We expected that MC, like other patients with Riddoch phenomenon, would show preserved functionality of motion-selective extrastriate cortex, particularly MT + , and indeed she did. As such, additional tests were done to determine the nature of her residual motion processing, particularly whether it included direction discrimination neurally and behaviorally.

\section{Case history}

MC is a right-handed female, born in 1969, with acquired bilateral occipitotemporal lesions (Fig. 1A). Note that our patient MC is different from another patient MC who demonstrates blindsight (Radoeva et al., 2008). Several previous reports have provided brief descriptions of our patient MC's case (Dutton, 2003) and have examined aspects of her condition including spared haptic object recognition despite impaired visual recognition (Snow et al., 2015), impairments in peripheral but not central auditory motion perception (Thaler et al., 2016), activation for sounds conveying material properties (Arnott et al., 2008), and spared affective processing of faces (Striemer et al., 2017). Nevertheless, this is the first comprehensive report of her history and fullest description of the lesioned and spared functional regions.

In February 1999, at age 30, MC experienced severe respiratory collapse and severe hypotension as a result of a lung infection. She remained in a coma for 52 days, during which time she suffered a bilateral occipital infarction as initially revealed by a computerized tomography (CT) scan.

Upon her initial arousal from the coma, she reported no sense of vision. Approximately six months later, she began to experience visual phenomena (such as her first phenomenological report of perceiving the reflections off a metallic gift bag) and described vivid sensations of color, "like fireworks going off." When she visited an ophthalmologist, Dr. Gordon Dutton (co-author), two years after the initial incident, she reported that she had no useful vision. Nevertheless, and much to her own surprise, she was able to mirror arm movements made by the examiner and to walk around obstacles (Dutton, 2003).

MC's everyday phenomenology is fascinating. For example, Dutton (2003, pp. 5-6) reported, "She can see rainwater running down a window but cannot see through it. When her daughter is walking away from her, she can see her daughter's pony tail moving from side to side but cannot see her daughter. She can see the movement of the water going down the plug hole but she cannot see her child in the bath." She described her visual experiences as "like being underwater," as if "you're standing at the top of a bridge and look down at a stream - the way water flows around with the current". She remarked that she can see outlines or blobs moving. Although she had noted such "weird" (in her words) phenomenology, she discounted its validity because of having been told that she was blind by a number of physicians. In fact, since meeting Dr. Dutton and in participating in these experiments, she frequently expressed a sense of vindication that her "strange" percepts were legitimized.

Dr. Dutton encouraged her to develop strategies to use motion and self-motion to improve her visual abilities and her confidence to trust them. Specifically, at his encouragement, she learned to make side-toside head movements and acquired a rocking chair. Moreover, she followed his advice to learn horseback riding at a school for the blind and became quite proficient at it, becoming able to guide the horse at a canter through a slalom course defined by traffic cones (See Supplementary Video, Part A). She no longer requires self-motion strategies to take advantage of her residual vision but reports that they were very helpful initially. She easily navigates through obstacles (See Supplementary Video, Part B) as could another patient with similar bilateral occipital lesions (de Gelder et al., 2008) and an experimental macaque named Helen with striate cortex lesions (Humphrey, 1974). MC can also catch balls that are rolled or thrown towards her, moving her arm to reach to the correct location and preshaping her hand appropriately, even when she is surprised by a different size than expected (See Supplementary Video, Part C). Although she can reliably describe the motion of stimuli, her descriptions of form are less reliable. As one example, she may clearly report the experimenter's hand moving toward her, but not be able to tell reliably whether the thumb is pointing up vs. down (See Supplementary Video, Part D). As another example, she reported that when she first became visually aware, occasionally she would reach down to the floor attempting to pick up a sunbeam or pattern on the carpet, unaware that it was not an actual object.

Supplementary material related to this article can be found online at http://dx.doi.org/10.1016/j.neuropsychologia.2018.05.008.

Over the past decade, MC's self-reports recorded in the clinical notes describe continuing improvements in her residual vision abilities. Clinical reports described abilities such as "reading" large letters by tracing their forms by hand (with an acuity of approximately $1 / 60$, improving to $1 / 12$ two years later when she no longer needed to trace the letters but could imagine or pantomime doing so). During early (2002) and later (2008) interviews, she reported palinopsia, the persistence of images such as colors, glare, and flash photographs for seconds to hours. She reports vivid sensations of color, especially red and yellow, though in case reports (2000) and in our own testing, her reported percepts often do not match the actual color.

Prior to her incident, MC worked as a secretary at a hospital eye 
clinic for ten years. She is intelligent, high-functioning, highly motivated, and very personable, upbeat, and cooperative. She displays no memory or cognitive deficits. She wears a prosthetic lower leg because of an amputation related to the respiratory collapse. In everyday life, she walks outdoors and on stairs with a cane and/or with assistance from family members; however, she said she mostly uses the cane to ensure that others realize she is blind and move out of the way. Nonetheless, she can detect the presence of stairs and obstacles and adjust her steps accordingly. She navigates inside her house without a cane or assistance. She learned Grade 1 Braille but found it too challenging to progress further (perhaps due to the absence of visual cortex; e.g., Cohen et al., 1997).

Goldmann perimetry (April 2011, carefully conducted by neuroophthalmologist Alex Fraser at Western's University Hospital in the presence of the senior author and reported in Thaler et al., 2016) revealed no detection of static visual targets but spared perception of moving targets presented in the upper left and lower right visual quadrants. Earlier perimetry results were mixed, with one report of spared motion processing across the visual field, particularly the lower right visual field (2001, according to case reports), one report failing to find any residual vision (2004, according to case reports), and one report indicating spared motion perception in the upper left visual field (June 2007, at Western's University Hospital). These may indicate either simple variability in quality of the perimetry testing or in MC's strategies and confidence. Alternatively, given that MC regularly reports verbally that her residual motion "keeps getting better", there may have been some functional recovery over the years; however, this possibility is speculative.

MC has difficulty sustaining visual fixation. She has strabismus, with concomitant left exotropia and hypertropia (i.e., her left eye deviates outward and upward). Though Goldmann perimetry in 2011 was conducted only when MC was looking straight ahead, in general her ability to maintain fixation is poor (as is typical of patients lacking foveal cortex). As such, calibration of an eye tracker is non-trivial, making it difficult to conduct eye tracking with any certainty.

\section{Structural magnetic resonance imaging}

MC's structural anatomy has been previously described in brief (Arnott et al., 2008; Snow et al., 2015; Thaler et al., 2016). Using structural data collected in 2011, we conducted an extensive characterization of her anatomy by mapping her lesion, co-registering her brain with the MNI template to enable comparisons with probabilistic atlases.

\subsection{Lesion mapping}

As shown in Fig. 1B and Supplemental Figure 1, a mask of MC's lesion extent was identified based on the T1-weighted structural image. The mask contained two grades. The first comprised voxels that did not have any clear remaining tissue. The second comprised voxels that contained tissue that was clearly abnormal. This included regions of grey matter where the cortical thickness was visibly thinner than comparable regions of the MNI template and white matter regions where the T1-weighted intensities were at least $20 \%$ less than that of white matter in non-damaged regions of MC's brain. These regions typically surrounded the first grade of the mask. The complete volume of MC's anatomical and lesion mask have been made publicly available (Arcaro, 2017).

\subsection{Anatomical registration with MNI template}

Given the extent of MC's lesion, standard anatomical registration methods yielded poor alignment with MNI template brain. To circumvent this issue, we first manually identified a brain mask of non-lesioned tissue from MC's T1-weighted structural volume and a comparable mask from the MNI template, then used a 12-parameter linear registration (FSL's FLIRT) on these masks to align the shape of MC's intact brain with the MNI template. This transformation was applied to MC's T1-weighted structural image, then a nonlinear registration (AFNI's 3dQwarp) was performed between a masked version of MC's anatomy that only included intact tissue and a comparably masked version of the MNI template. This nonlinear transformation was applied to MC's unmasked T1 anatomical image, to the lesion mask, and all functional datasets for mapping to the MNI template.

\subsection{Probabilistic atlases}

Two probabilistic atlases were registered to the MNI template: (1) A probabilistic atlas of 25 retinotopic areas (Wang et al., 2015) spanning occipital cortex (V1, V2, V3, hV4), ventral temporal cortex (VO1, VO2, PHC1, and PHC2), lateral occipital cortex (LO1, LO2, TO1 / hMT, TO2 / MST), dorsal extrastriate (V3A, V3B), posterior parietal (IPS0, IPS1, IPS2, IPS3, IPS4, IPS5, SPL1), and frontal cortex (FEF, IFS). (2) A probabilistic atlas of anatomically defined MT based on cytoarchitecture (hOC5; Malikovic et al., 2007). A map of brain regions most likely to show motion-selective activity was generated through a Neurosynth meta-analysis of 383 studies for regions active in experiments that involved "motion" as a reverse inference (neurosynth.org; Yarkoni et al., 2011). A surface model of the MNI template was used to visualize correspondence between these probabilistic atlases and MC's lesion map and to ensure reasonable co-registration.

\subsection{Characterization of lesioned regions}

MC's lesion comprises most of occipital cortex bilaterally and extends into posterior temporal cortex bilaterally and right parietal cortex (Fig. 1B, Supplemental Figure 1). Some spared tissue is present in the anterior calcarine sulcus bilaterally, parts of the collateral sulcus bilaterally, lateral occipital cortex including anterior parts of the lateral occipital sulcus bilaterally, and the intraparietal sulcus in the right hemisphere. To assess the relationship between MC's lesions and visual areas, a map of her lesion was projected onto the MNI template and compared with a probabilistic atlas of retinotopic areas (Wang et al., 2015). Lesioned tissue comprised visual areas V1, V2, V3, hV4, V3A, $\mathrm{V} 3 \mathrm{~B}, \mathrm{VO} 1, \mathrm{VO} 2$, and approximately the posterior half of TO1 bilaterally. The lesion also covered VO2, PHC1, and PHC2 in the left hemisphere. Tissue covering most of IPSO-4 and PHC1-2 in the right hemisphere was abnormal with relatively thin grey matter and dark surrounding white matter (as compared to the MNI volume template). Abnormal tissue was also identified within anterior parts of V1 and V2 as well as parts of the fusiform and collateral sulcus in the right hemisphere.

MC's lesion spared at least part of the cortex where the motion-selective MT+ complex would be expected. Human fMRI studies have distinguished some of the subdivisions of the MT + complex (Dukelow et al., 2001; Huk et al., 2002). However, the correspondence between functionally defined, retinotopy-defined and cytoarchitectonically defined cortical fields in this vicinity remains tentative (Amano et al., 2009; Bridge, Clare, \& Krug, 2014), making it difficult to determine which specific portions are intact vs. damaged in MC. MC's lesion appeared to largely spare tissue in the expected location of a human occipital region, hOc5, proposed as equivalent to MT + (Malikovic et al., 2007; See Supplemental Figure 2). However, as shown in Fig. 1B (and Supplemental Figure 2), the lesion overlapped with the posterior end of the expected locus of one motion-sensitive retinotopic area in temporaloccipital cortex, TO1, suggested as the human homologue of MTproper, but largely spared adjacent motion-sensitive area TO2, suggested as the human homologue of MSTl (Amano et al., 2009). Tissue within TO2 and the non-lesioned parts of lateral occipital cortex appeared abnormal with thinned grey matter. Comparisons with the Neurosynth meta-analytic database suggested that MC's lesions largely 
spared the regions most commonly activated by studies involving "motion" (Supplemental Figure 2). In sum, comparisons of MC's brain with three atlases from typical participants (based on cytoarchitectonic, retinotopic and functional criteria) suggest that the tissue in MC's MT + is at least partially spared, if not entirely normal. As such, fMRI will provide a valuable means to assess the functionality of this region.

Thalamic visual structures appeared at least partially spared. The LGN appeared atrophied in both hemispheres. There was also a small lesion within the left posterior thalamus anterior to the visual pulvinar (Supplemental Figure 1B; Arcaro et al., 2015), and overlapped with subregions of somatosensory VP (Krauth et al., 2010; Morel et al., 1997). The medial pulvinar was located just posterior to the lesion, but did not overlap. Given some imprecision in the registration and individual variability, it is possible that the lesion includes anterior-most parts of the medial pulvinar.

\section{Methods}

In brief, due to geographic constraints, MC was tested across multiple sessions over several years. Results are presented chronologically. We began with initial psychophysical and fMRI tests in 2007 (University of Western Ontario), which suggested the foundations for her Riddoch phenomenon - spared motion perception and spared processing in MT +. fMRI tests were replicated and extended in later sessions (2009, Maastricht University; 2011, University of Western Ontario). Extensive psychophysical testing was conducted June and September 2013, in Glasgow and at Durham University, respectively with some stimuli using similar parameters as in the fMRI scans.

Psychophysical tests from 2007 showed similar effects as those from 2013 (motion detection abilities, highest sensitivity to low spatial and high temporal frequencies, especially $4 \mathrm{~Hz}$ ). Although results from 2007 provided some guidance for fMRI studies, they have not been included here for conciseness and because they used criterion-dependent methods ("Did you see motion? Yes/no"); whereas, the 2013 methods used criterion-free methods ("Did you see motion in the first or second interval?") and included much more testing.

\subsection{Functional magnetic resonance imaging}

\subsubsection{Motion-selectivity: Moving vs. stationary checkerboards}

Given MC's spared motion perception, we initially examined whether her brain, particularly the middle temporal motion complex, MT +, showed preferential activation to moving vs. stationary stimuli. Data was collected on two occasions to compare activation for a moving checkerboard to a stationary checkerboard (in 2007), sometimes also in comparison to a blank screen (in 2008). The checkerboard loomed and receded (changing direction every $2 \mathrm{~s}$ ), with radial motion chosen to minimize the likelihood of eye movements. MC was instructed to try to gaze at a red fixation point in the centre of the display; however, given her problems maintaining fixation, it is unlikely that she was able to do so. Nevertheless, given that our interest is in whether she shows responses to motion or not, it is not critical whether the visual motion arose from stimulus motion and/or retinal motion.

In 2007, the display cycled through 16-s blocks of stationary and moving checkerboards of $30^{\circ}$ diameter (run duration $=3 \mathrm{~min}, 24 \mathrm{~s} \times 5$ runs). Data were collected on a 4-Tesla Varian-Siemens UNITY INOVA whole-body imaging system at the University of Western Ontario using a single-channel occipital surface coil. Functional data (T2*-weighted, gradient-echo echoplanar imaging) were collected at a resolution of $3 \mathrm{~mm} \times 3 \mathrm{~mm}$ in-plane $\times 4 \mathrm{~mm}$ slice thickness ( $\times 25$ slices) with a volume acquisition time of $2 \mathrm{~s}$ (based on 2 segments/plane at a time to repeat, $\mathrm{TR},=1000 \mathrm{~ms}$; time to echo, $\mathrm{TE}=15 \mathrm{~ms}$; flip angle $=60 \mathrm{deg}$, navigator-echo-corrected). Anatomical (T1-weighted) scans were collected at a 1-mm isotropic resolution.

In 2008, the display cycled through 16-s blocks of a blank screen, a static checkerboard, and a checkerboard that oscillated inward and outward (run duration $=5 \mathrm{~min}, 4 \mathrm{~s} \times 4$ runs in two sessions). Data were collected on a Siemens 3-Tesla Allegra scanner at the University of Maastricht with a single-channel head coil. Functional data were collected at a $3.5-\mathrm{mm}$ isotropic resolution $[\mathrm{TR}=2 \mathrm{~s}$; TE $=30 \mathrm{~ms}$; flip angle 90 deg.; 32 slices. Anatomical scans (ADNI MPRAGE) were collected at $1-\mathrm{mm}$ isotropic resolution.

\subsubsection{Visual responsiveness: Flickering checkerboards}

To evaluate general visual responsiveness in MC's visual system, in 2011 we examined whether cortical and subcortical structures showed increases in activity during viewing of checkerboard stimuli counterphase flickering at $4 \mathrm{~Hz}$. We also examined whether contrast response functions would be similar to those found in typical participants, with strong gains in activation as a function of contrast for early visual areas V1, V2, and V3, but not MT + (Kastner et al., 2004; Tootell et al., 1995). Three levels of root-mean-square contrast were used: $5 \%, 40 \%$, and $100 \%$. Full-field $\left(30^{\circ}\right.$ diameter) checkerboard stimuli were presented in blocks of $17.5 \mathrm{~s}$ and alternated with equally long presentations of black screens as a baseline condition. During a given run, each contrast condition was presented three times in pseudorandom order with the constraint that all conditions were presented prior to the next repetition (run duration $=5$ mins, $37.5 \mathrm{~s} \times 3$ runs). A total of 15 blocks were collected for each contrast level. Data were collected on a 3-Tesla Siemens TIM Trio scanner at the University of Western Ontario with a 12channel head coil. Functional data were collected at a 2-mm isotropic resolution $[\mathrm{TR}=2.5 \mathrm{~s} ; \mathrm{TE}=40$; flip angle $=70 ; 37$ slices $]$. Anatomical (T1-weighted) scans were collected at 1-mm isotropic resolution.

\subsubsection{Direction-selective adaptation for random dots}

In 2011, we used an fMRI adaptation paradigm (Grill-Spector et al., 1999) to determine whether activation in MT + (and other regions) would show direction-selective adaptation for RDKs, as shown previously in neurologically intact participants (Konen and Kastner, 2008). That is, we tested whether motion responses would be reduced when motion direction was repeated vs. variable, a population-level signature of direction-selective neurons.

Pilot psychophysical tests (2007) suggested that MC had high sensitivity to low spatial frequencies and high temporal frequencies (replicated with more rigor in 2013, see Sections 4.2.2.1 and 5.2.2.1). As such, in fMRI pilot testing, we first showed MC a variety of dot patterns to see which patterns evoked the strongest sense of motion. In fact, MC was unable to perceive any motion in the conventional displays. Based on this, rather than the fine RDK displays previously used for typical participants (e.g., 1000 dots with $0.15^{\circ}$ diameter; Konen and Kastner, 2008), we used a display with fewer (50) and larger $\left(2.85^{\circ}\right)$ dots within a $30^{\circ}$ circular aperture at a velocity of $22^{\circ} \%$ s.

Moving dot stimuli were presented in 16-s blocks in which random dots moved continuously in one direction (adapted blocks) or changed direction every second (non-adapted blocks). We investigated two conditions of optic flow: planar and radial motion. In planar motion, dots moved leftward or downward. In radial motion, random dots moved away from the central point of the screen. Within a non-adapted block, motion directions were presented in pseudorandom order with the constraint that all conditions were presented prior to the next repetition. Each run consisted of six blocks (three adapted and three nonadapted) of moving dots and alternated with equally long presentations of stationary dots. Each run started and ended with a blank (no visual stimulation) period that lasted for $20 \mathrm{~s}$. The order of specific motion directions was randomized across scans (run duration $=3$ mins, $52 \mathrm{~s} \times$ 5 runs). A total of 15 adapted and 15 non-adapted blocks $(5 \times$ motion direction) were collected. Data were collected on a 3-Tesla Siemens TIM Trio scanned at the University of Western Ontario with a 12-channel head coil. Functional data were collected at a 3-mm isotropic resolution $[\mathrm{TR}=2 \mathrm{~s} ; \mathrm{TE}=30$; flip angle $=70 ; 37$ slices $]$. Anatomical (T1weighted) scans were collected at 1-mm isotropic resolution. 


\subsubsection{Resting-state functional connectivity}

In 2011, we collected a single, 8-minute rest scan for functional connectivity analyses. The lights were turned off in the scanner and no visual stimuli were presented. MC was instructed to remain still for the duration of the scan and to keep her eyes shut. Functional data were collected at a $3-\mathrm{mm}$ isotropic resolution [TR $=2 \mathrm{~s}$; TE $=30$; flip angle $=70 ; 37$ slices $]$.

\subsection{5. fMRI preprocessing and data analysis}

Functional scan data were analyzed using Analysis of Functional NeuroImages (AFNI), SUMA, Freesurfer, BrainVoyager, and MATLAB. For each scan session, all images were aligned to a single time point for that session, detrended and motion corrected. The experiment on moving vs. stationary checkerboards (Section 4.1.1) and ROI analyses for other experiments (sections 4.12, 4.13) used spatially unsmoothed data; all analyses that involved mapping to the MNI surface (Sections 4.1.2, 4.1.3, 4.1.4) used data that were spatially filtered using a Gaussian filter of $4 \mathrm{~mm}$ full-width at half maximum. This smoothing kernel was chosen to increase signal to noise ratio while maintaining spatial specificity. The spatial filtering also improved volume-to-surface mapping by compensating for small imprecisions in the registration between MC's brain and the MNI template. Each scan was normalized to its mean. A multiple-regression analysis in the framework of a general linear model was performed on the localizer experiments. Each stimulus condition was modeled with a canonical hemodynamic response function. For later data (excluding moving vs. flickering checkerboards), additional regressors that accounted for variance due to baseline shifts between scans, linear drifts, and head motion parameter estimates were also included in the regression model. Due to the time course normalization, beta coefficients were scaled to reflect percentage signal change. Data for the moving vs. stationary checkerboards was aligned Talairach space and resampled at a 3-mm isotropic resolution.

\subsubsection{Analysis of motion direction and alternating contrast checkerboard} experiments. To estimate the response magnitude for each stimulus block within an ROI, the mean signal was extracted and block responses were normalized (to motion onset for the moving vs. stationary checkerboards and to the mean activity during $4 \mathrm{~s}$ preceding stimulus onset for other data). The time window corresponding to the peak activity for each block (8-18 s for motion adaptation and 7.5-17.5 s for checkerboard contrast) was averaged to derive estimates of the response for each stimulus condition. For the contrast experiment, an analysis of variance (ANOVA) was run for each ROI to evaluate whether activity across blocks varied as a function of contrast. Post-hoc t-tests were conducted when appropriate. For the motion adaptation experiment, an unpaired t-test was run for each ROI to evaluate whether activity across blocks significantly differed between adapted and non-adapted conditions. An analysis of variance was also run to assess whether activity varied across the three motion adaptation types.

4.1.5.2. Analysis of functional connectivity data. For correlation and ICA analyses, several additional steps were performed on the data: (1) removal of signal deviation $>2.5$ SDs from the mean (AFNI's 3dDespike); temporal filtering retaining frequencies in the $0.01-0.1 \mathrm{~Hz}$ band; (3) linear and quadratic detrending; and (4) removal by linear regression of several sources of variance: (i) six motion parameter estimates (three translation and thee rotation) and their temporal derivatives, (ii) the signal from a ventricular regions, (iii) the signal from a white matter region, (iv) the signal from the lesion region. Global mean signal removal was not included in the analysis. To minimize the effect of any evoked response due to the scanner onset, the initial 10 (20 s) TRs were removed from the rest scan. Seed-based Pearson correlation and independent component analyses (ICA) were conducted on rest data. Regions of interest for correlation analyses were defined based on the motion localizer in 2011 .

\subsection{Psychophysical testing}

Psychophysical tests were run for a variety of stimuli: checkerboards, RDKs, gratings and dots to address behavioral performance useful for interpreting fMRI data. Stimuli were run using VPixx software (v. 2.8.4; VPixx Technologies Inc.) on a calibrated MacBook Pro laptop and its internal screen or a Mac Mini with a Samsung SyncMaster 2333 monitor (60-Hz refresh rate). MC was tested across four days (in June \& Sept. 2013). Viewing distance was $57 \mathrm{~cm}$. Testing relied on forcedchoice procedures that are criterion-free.

\subsubsection{Random dot kinematograms}

We examined MC's ability to detect motion and discriminate motion direction using RDKs with parameters comparable to those used for fMRI testing. The display subtended $30^{\circ}$ of visual angle. Given possible differences between linear and complex motion, we examined three categories of movement: translation (left/right and, in some cases, up/ down), flow (expansion/contraction) and rotation (clockwise/counterclockwise). Fifty dots diameter $2.85^{\circ}$ moved at a speed of $22^{\circ}$ (visual angle)/s (for translation and expansion/contraction and $90^{\circ}$ (rotational angle)/s (for rotation)) with an unlimited lifetime. Dots were white on a black background for a contrast near 100\% (Macbook Pro screen: white $=127.1 \mathrm{~cd} / \mathrm{m}^{2} ;$ black $=1.4 \mathrm{~cd} / \mathrm{m}^{2} ;$ maximum Michelson contrast $=$ 97.8\%; Mac Mini with SyncMaster: white: $202.8 \mathrm{~cd} / \mathrm{m}^{2}$; black = $0.2 \mathrm{~cd} / \mathrm{m}^{2}$; maximum Michelson contrast $\left.=99.8 \%\right)$.

4.2.1.1. Motion detection. On each trial, an RDK was shown that was either stationary or moving at $100 \%$ coherence for $6 \mathrm{~s}$. MC had to make a 2-alternative forced-choice decision about whether the stimulus was moving or stationary. In total, MC completed 120 trials for translation (80 left-right; 40 up-down), 160 trials for rotation, and 80 trials for flow. Trials were grouped by motion category in blocks of 40 .

4.2.1.2. Motion category discrimination. On each trial, an RDK with $100 \%$ coherence was shown for $6 \mathrm{~s}$, reversing direction every $2 \mathrm{~s}$ within one of the three categories of motion (translation, flow or rotation). MC had to make a 3-alternative forced-choice decision about which category of motion was shown. In total, MC completed 120 trials (in blocks of 30).

4.2.1.3. Opposite motion direction discrimination. On each trial, a RDK was shown that moved in one of two opposite directions with $100 \%$ coherence for $6 \mathrm{~s}$. MC had to make a 2-alternative forced-choice decision about which of the two directions was shown. In total, MC completed 240 trials (60 left-right translation, 20 up-down translation, 60 rotation, 100 flow) in blocks of 20 grouped by motion category.

4.2.1.4. Opposite motion direction discrimination as a function of coherence. On each trial, an RDK was shown for $6 \mathrm{~s}$ in which a certain percentage of the dots (3.125-100\%) moved coherently while the others moved randomly. MC had to make a 2-alternative forcedchoice decision about which of the two motion directions was shown. In total, MC completed 1008 trials (432 left-right; 192 up-down; 192 rotation; 192 flow) in blocks of 48 .

\subsubsection{Gratings and bars}

4.2.2.1. Gratings: Spatiotemporal sensitivity. To characterize MC's spatiotemporal sensitivity profile, MC was presented with trials containing two sequential stimuli, one of which had a vertically oriented sine-wave grating that could move right or left and that filled the rectangular display. MC had to make a 2-alternative forcedchoice decision about which interval contained the moving grating. Gratings were presented at four spatial frequencies $(0.5,1,2$, or 4 cycles $\left./^{\circ}\right)$ and four temporal frequencies $(0,2,4$, or $8 \mathrm{~Hz})$. MC performed six blocks of testing (12 trials/spatiotemporal combination) for a $100 \%$ contrast grating presented for $500 \mathrm{~ms}$ or $2000 \mathrm{~ms}$ (which didn't affect 
performance, so data were collapsed).

4.2.2.2. Grating and bar motion. To test whether MC's direction discrimination was poorer for complex than simple stimuli, as suggested by other patients with blindsight (Azzopardi and Cowey, 2001), we showed her either a square-wave grating or a single bar that moved in one of four directions orthogonal to its orientation (vertical stimuli moved left or right; horizontal stimuli moved up or down) for a duration of $2 \mathrm{~s}$. MC had to make a 4-alternative forced-choice decision about which of the four motion directions was shown. In total, MC completed 120 trials for the grating stimulus and 80 trials for the bar stimulus in blocks of 40 . Both the grating and bar had 100\% contrast (black bars on white background in a square-wave profile). The stimulus subtended $16^{\circ}$ (grating and bar) $\mathrm{x} 16^{\circ}$ (grating) or $1^{\circ}$ (bar). Because the grating had a spatial frequency of 0.5 cycles $/{ }^{\circ}$, there were 8 black bars and 8 white bars, each $1^{\circ}$ wide, equivalent to the width of the single bar. Both the grating and the bar drifted at $8^{\circ} / \mathrm{s}$ (corresponding to a temporal frequency of $4 \mathrm{~Hz}$ for the grating) as smoothly as possible given the maximum refresh rate of the monitor $(60 \mathrm{~Hz})$. In sum, the size and velocity of the single bar equated to those for one bar of the grating.

\subsubsection{Checkerboards: Contrast response functions}

We examined MC's contrast response functions across a range of Michelson contrast levels (100\%, 40\%, 20\%, 10\%, 5\%, 2.5\%, 1\%, 0.5\%) that included those tested with fMRI (100\%, 40\% and 5\%). On each trial, MC was presented with two sequential stimuli, one of which showed a checkerboard flickering at $4 \mathrm{~Hz}$ and the other a blank screen. MC had to make a 2-alternative forced-choice decision about which interval contained the flickering checkerboard. The monitor was calibrated to ensure accurate contrast levels. The checkerboard included 24 radial cycles x 6 concentric cycles on a grey screen. MC completed 40 trials per contrast level (10 blocks of 32 trials/block over two testing days).

\section{Results}

\subsection{Functional magnetic resonance imaging}

\subsubsection{Motion-selectivity: Moving vs. stationary checkerboards}

To assess which regions could support MC's preserved motion perception, motion responses were measured throughout visual cortex with fMRI. MC had dramatic nonverbal and verbal responses when she first saw moving checkerboards. We were unable to use an eye tracker in the scanner; nevertheless, we aimed an MR-compatible bore camera (MRC Systems) toward her eyes to approximately monitor her gaze, which did shift, particularly up and down. At the onset of the first block of a moving checkerboard, MC's eyes began watering and her cheek moved, as seen through the bore camera. At the end of that scan, when asked if she saw motion, said, "That was amazing. I could see thousands of things. I've never seen so much motion. I can't believe it! I was crying and laughing."

fMRI scanning in 2007 and 2008 revealed that MC showed motion-

A.
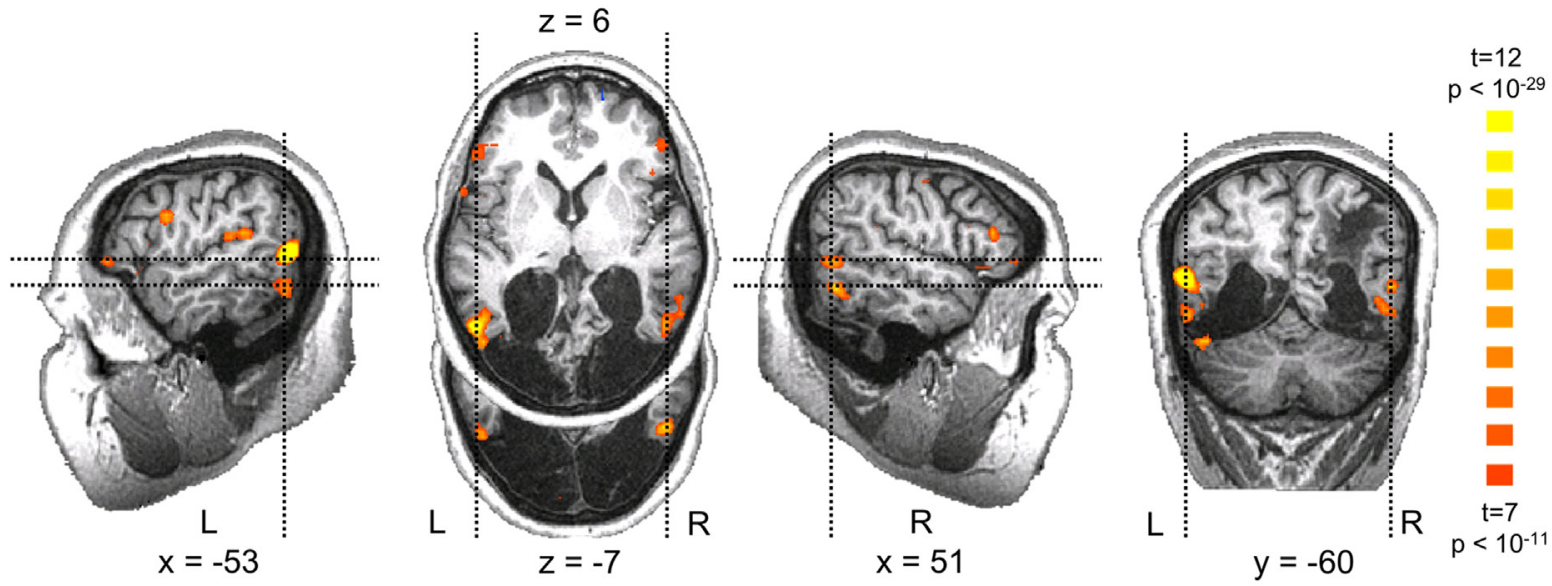

B.
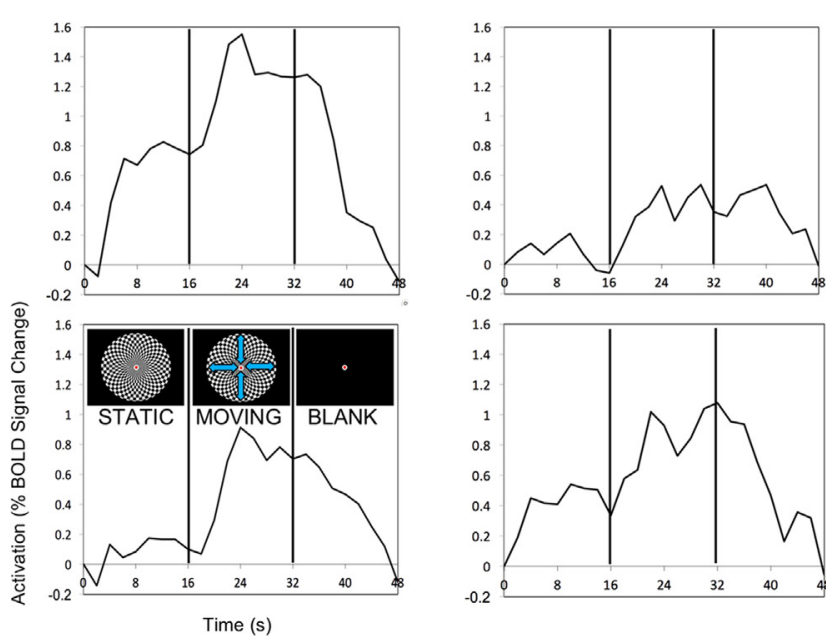

$\mathrm{RH}$ dorsal MT+

LH dorsal MT+

$\mathrm{LH}$ ventral MT+

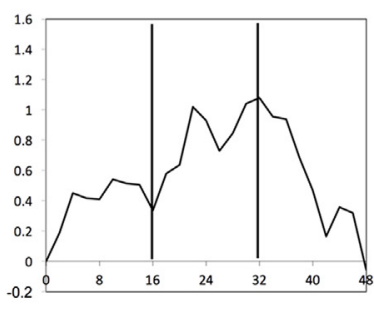

$\mathrm{RH}$ ventral MT+

Fig. 2. Motion responses in MT + for looming/receding vs. static checkerboards. (A) MC was scanned while viewing 16-s blocks of a static checkerboard, a looming/receding checkerboard and a blank screen. A contrast of moving > stationary revealed strong activation in dorsal and ventral subregions of MT + in both hemispheres. Slice planes are specified in Talairach coordinates and indicated by dashed lines in orthogonal slices. (B) Time courses of activation extracted from subregions in A show the expected rise in activation with the onset of motion and decline with the offset, consistent with the hemodynamic response function. Activation was particularly robust in left dorsal MT + . 

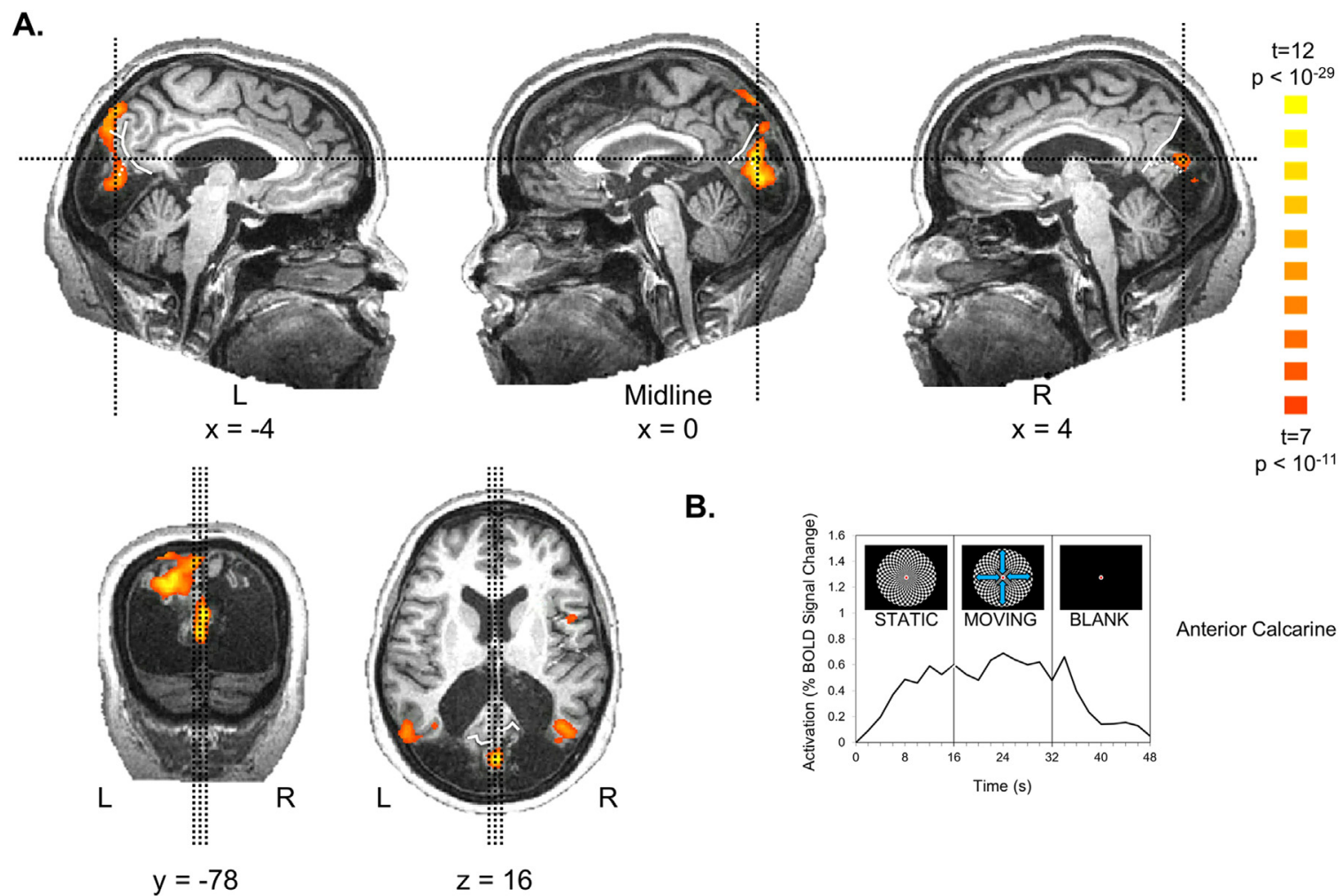

B.

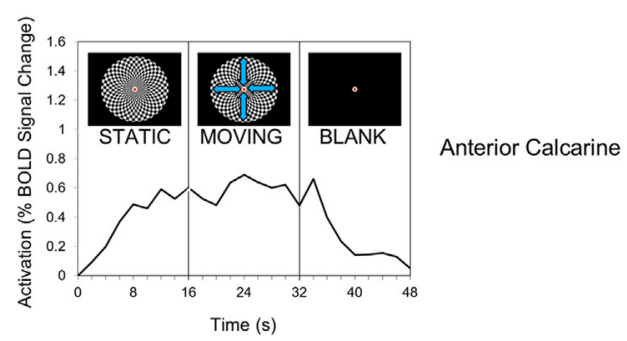

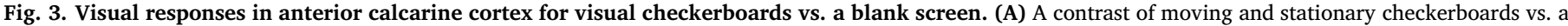

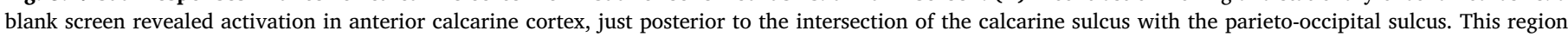

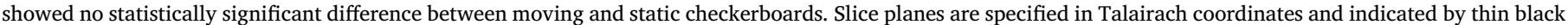

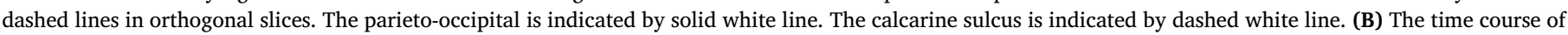

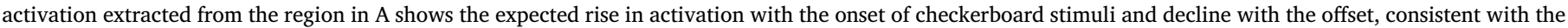
hemodynamic response function.

selective activation within MT+ (Fig. 2 and Supplemental Figure 3, which shows considerable intersession consistency even across years and scanners). Based on previous studies in neurologically intact participants, MT + activation would be expected near the junction of the inferior temporal and lateral occipital sulci (Watson et al., 1993), often in the ascending limb of the inferior temporal sulcus (Dumoulin et al., 2000). Motion-selective activation in MC's brain lay at the posterior edge of MC's spared tissue and included two clusters in each hemisphere
A.

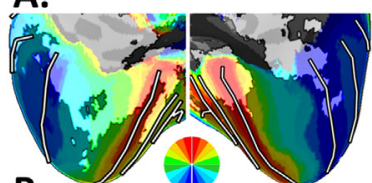

B.
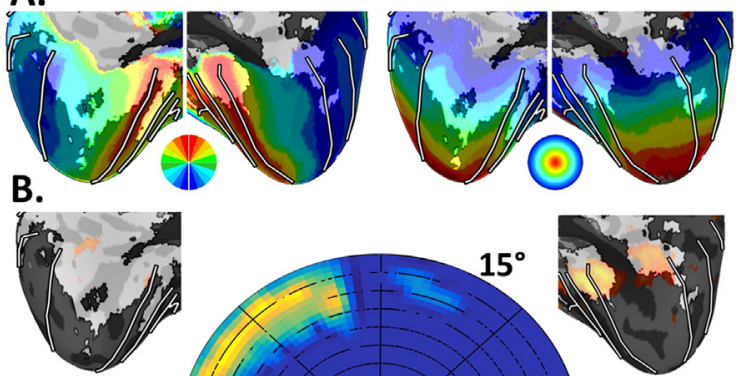

C.

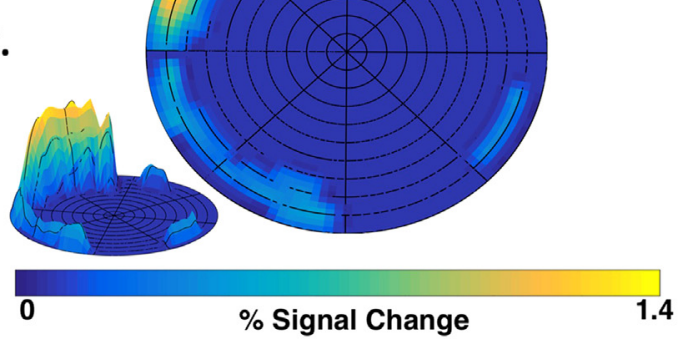

D.

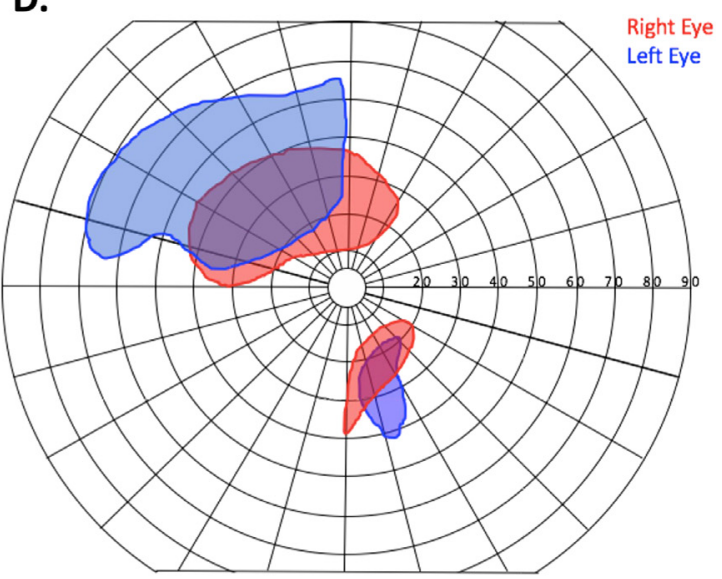

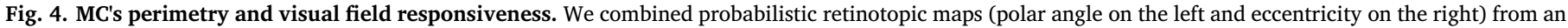

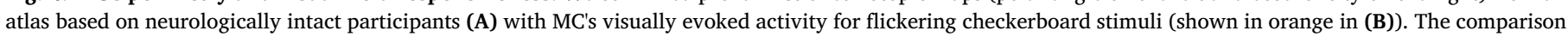

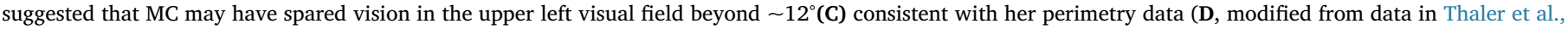
2016), which indicated sparing of sensitivity for moving (but not static) targets within the upper left visual field beyond $\sim 10^{\circ}$. 
consistent with the sulcal location of MT+: (1) dorsally, within the ascending limb of the inferior temporal sulcus and (2) ventrally within the inferior temporal sulcus. Though it is tempting to suggest that the enhanced activation in 2008 compared to 2007 may indicate some recovery of $\mathrm{MT}+$, consistent with MC's self-reports that her motion perception improved, substantive differences between scanners and protocols may account for the differences.

In addition to the activation in MT +, MC also showed activation in the anterior calcarine sulcus, just posterior to its intersection with the parieto-occipital sulcus, POS, as shown in Fig. 3. This region was activated comparably by both moving and static checkerboards compared to a blank screen but showed no significant motion selectivity. Activation was also observed in the expected location of left human V6/ V6A (also known as superior parieto-occiptial cortex) at the anterior POS (Pitzalis et al., 2006, 2013).

A recent human fMRI study (Mikellidou et al., 2017b) suggests the POS-calcarine intersection is the site of a scarcely studied but intriguing motion-selective visual area, prostriata, previously only reported in other primates (reviewed in Rockland, 2012; e.g., Yu et al., 2012). The boundary between human prostriata and adjacent V1 has a mirror reversal of eccentricity maps and prostriata disproportionately represents

A.

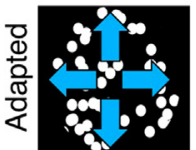

1s
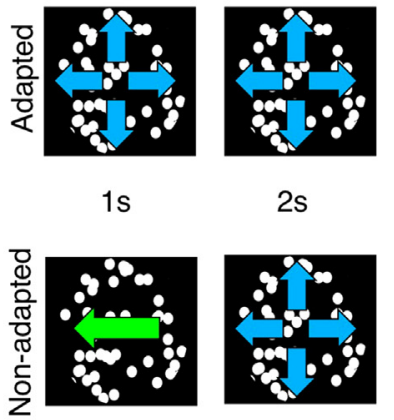

$2 \mathrm{~s}$
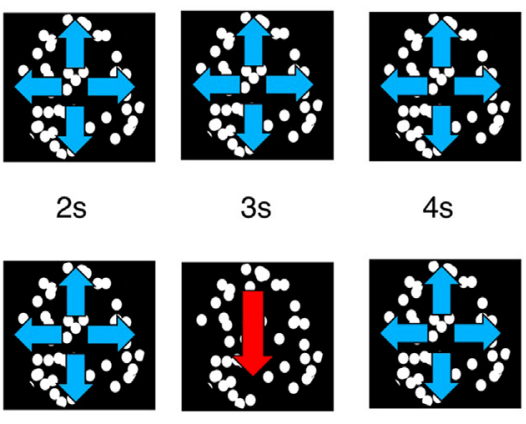

$3 s$

\section{$4 s$}
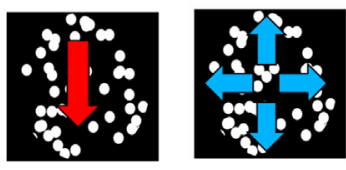

B.

\section{C.}

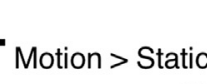

far peripheral vision (Mikellidou et al., 2017b). Because we were unable to obtain retinotopic maps in MC (due to her inability to maintain fixation), we cannot definitively determine whether her anterior calcarine activation focus corresponds to prostriata or anterior visual cortex, both of which represent the visual periphery. Based on the neuroanatomical locus (posterior to the parieto-occipital sulcus) and Talairach coordinates, MC's anterior calcarine focus appears more medial, posterior and superior than the expected prostriata focus $(\mathrm{x}=0, \mathrm{y}=-78, \mathrm{z}=16$; compared to $\mathrm{x}=-20, \mathrm{y}=-61, \mathrm{z}=1$ in Mikellidou et al., 2017a).

\subsubsection{Visual responsiveness: Flickering checkerboards}

To assess whether any of MC's other remaining visual cortex was functional, visual responses were measured throughout visual cortex with fMRI. Visual responsiveness was assessed by contrasting blocks of full-field, full-contrast checkerboard stimulation flickering at $4 \mathrm{~Hz}$ interleaved with blank periods (Supplemental Figure 4). Increased activity to checkerboard stimulation was observed in parts of anterior calcarine cortex in the right hemisphere (corresponding to peripheral V1 representing the left hemifield), ventral temporal cortex within and around the collateral sulcus in the right hemisphere, lateral temporal
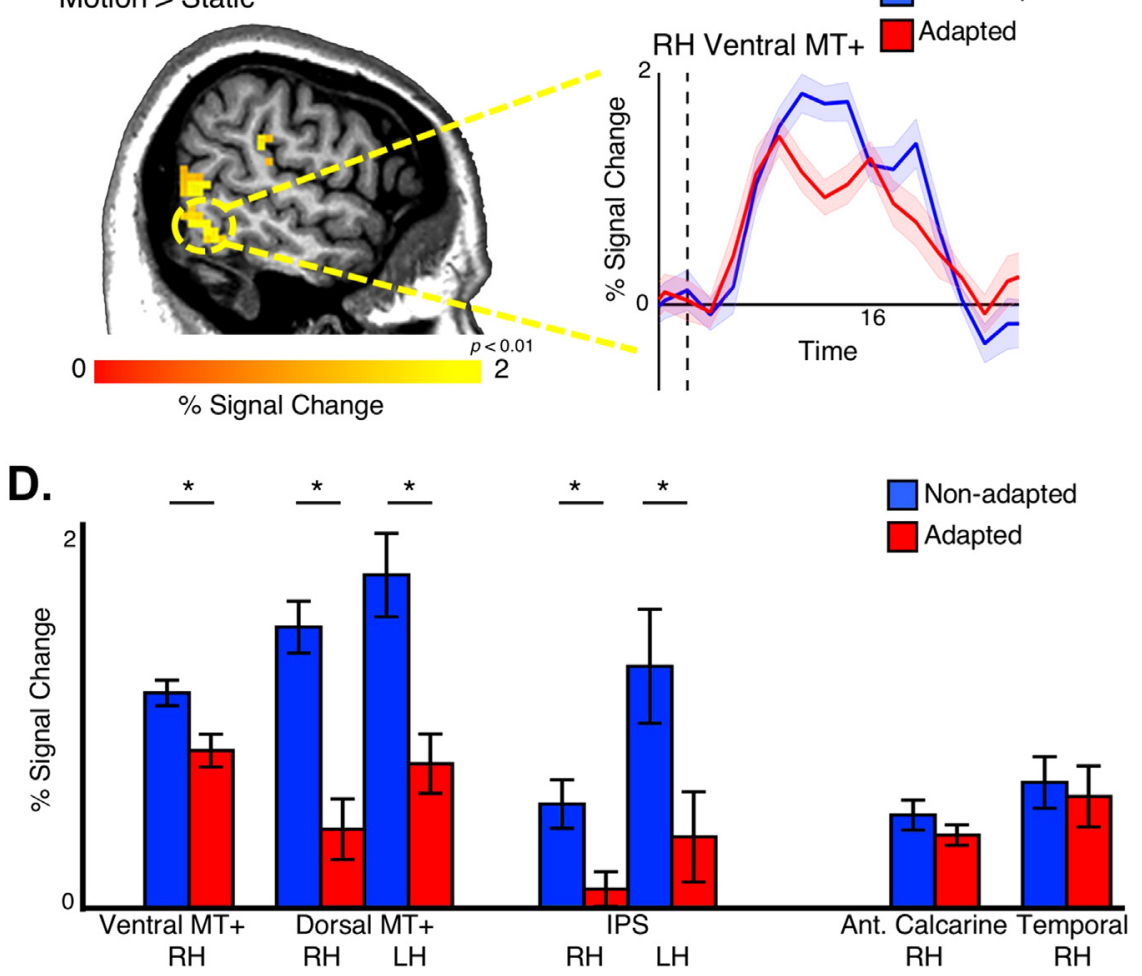

Fig. 5. Motion direction selectivity. (A) MC viewed blocks in which coarse RDKs moved in the same direction on every trial (adapted condition) or changed from trial to trial (non-adapted condition) in 16-s blocks. (B) Significantly greater activity to moving vs. static dots was observed within right dorsal and ventral MT + (as well as right ventral MT + , not shown) ( $p<0.01$, uncorrected). (C) In right ventral $\mathrm{MT}+$, activation was significantly higher for non-adapted vs. adapted motion blocks, a signature of direction selectivity. Vertical dashed line marks stimulus onset. Shaded region illustrates SEM across blocks. (D) Sensitivity to motion direction observed in dorsal subdivision of MT + bilaterally as well as motionsensitive regions of the intraparietal sulcus. Motion direction sensitivity (or motion sensitivity in general) was not observed in occipital or ventral temporal cortex.

Non-adapted

Adapted

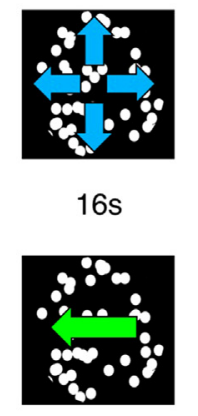


cortex within and around the inferior temporal sulcus bilaterally, and anterior parietal cortex in the left hemisphere (Supplemental Figure 4A, $\mathrm{p}<0.0001)$. Subcortical activity within the LGN and superior colliculus (SC) was observed at a lower threshold (Supplemental Figure 4B; $\mathrm{p}<0.01$ ).

Visual responses within MC's anterior calcarine cortex were consistent with the visual field locations in which she can perceive moving (but not static) targets. MC's visually evoked responses were compared with a probabilistic map of V1's visual field coverage in typical participants (Fig. 4A; Wang et al., 2015). Note that because we did not measure retinotopy in MC herself (due to her inability to maintain fixation), any comparison with maps from typical participants is necessarily speculative. Also note that probabilistic maps in controls predated the discovery of human prostriata (Mikellidou et al., 2017b) and mapping only extended to $15^{\circ}$ eccentricity; as such, this data does not enable us to distinguish $\mathrm{V} 1$ from prostriata.

Visual activity to checkerboards in MC was only detected within zones that represent eccentricities greater than $13^{\circ}$ (Fig. $4 \mathbf{B}+\mathbf{C}$ ). The strongest visual responses were localized to the upper left periphery, consistent with MC's spared visual sensitivity from perimetry as described in an earlier report (Fig. 4D; Thaler et al., 2016). Though the fMRI mapping in typical participants only extended to $15^{\circ}$ eccentricity (vs. $90^{\circ}$ eccentricity in perimetry testing in MC), MC has intact tissue anterior to the V1 activity, corresponding to further peripheral parts of V1 and/or area prostriata, suggesting that this tissue would have been visually responsive if stimulated. Though MC maintained fixation during perimetry testing (verified by eye monitoring), she was unable to maintain fixation during fMRI scanning (during which no eye monitoring occurred). Thus, the correspondence between the spatial representation of MC's perimetry and fMRI activation should be interpreted with some caution.

To further test the functionality of this remaining tissue in occipital cortex, responses to the checkerboard stimulus were assessed at three different contrasts (5\%, 40\%, and 100\%; Supplemental Figure 4C-D). Previous examinations of contrast response functions in typical participants found that while the fMRI signal increased as a function of contrast in most visual areas (V1-V4A) and LGN, the MT + response showed little or no gain (Kastner et al., 2004; Tootell et al., 1995).

Within the spared part of anterior calcarine cortex, activity across blocks varied as a function of contrast (ANOVA, main effect of contrast; $\mathrm{F}(2,42)=5.23 ; p=0.009)$. Anterior calcarine cortex activity increased monotonically from $5 \%$ to $40-100 \%$ contrast. Post-hoc unpaired t-tests, revealed a significant difference between $5 \%$ and $100 \%$ contrasts $(\mathrm{t}$ $(28)=3.34 ; p=0.002)$ and a between $5 \%$ and $100 \%(\mathrm{t}(28)=2.01$; $p=0.05$ ). The mean responses across contrasts also varied for ventral temporal cortex and the LGN in the right hemisphere, but these differences were not significant $(\mathrm{F}(2,42)<0.93 ; p>0.41)$. The signal within the LGN was particularly noisy, likely due in part to the small number of voxels. Results from MT + were uncertain: although activity appeared to increase with contrast for both dorsal and ventral subdivisions, statistically the effects did not reach significance. Taken together, these results suggest that the remaining tissue in MC's occipital cortex has at least some preserved visual function and could potentially support her preserved visual sensitivity.
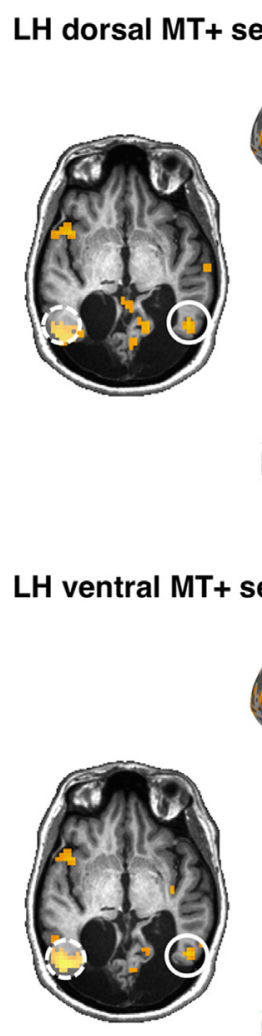
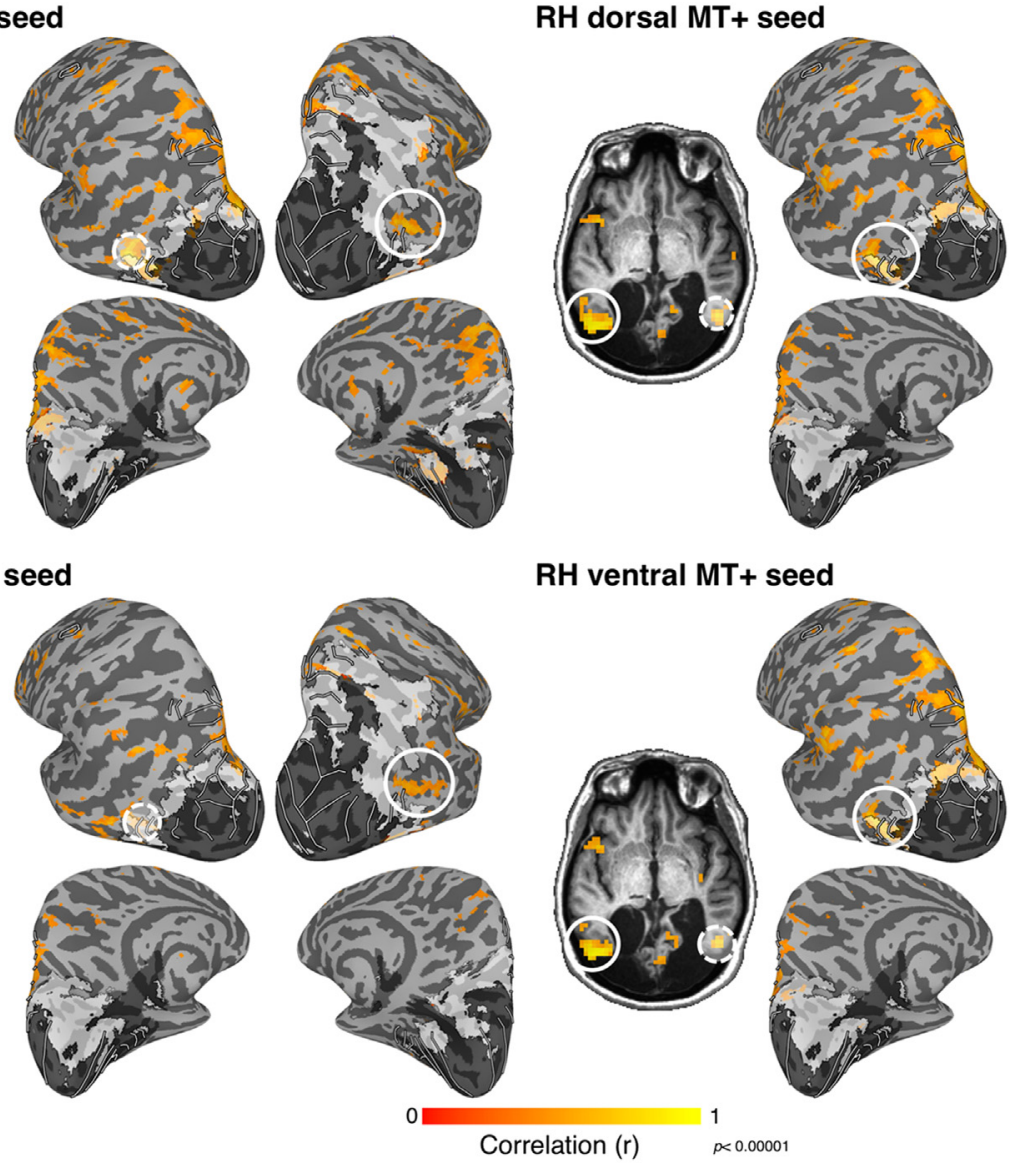

\section{RH dorsal MT+ seed}
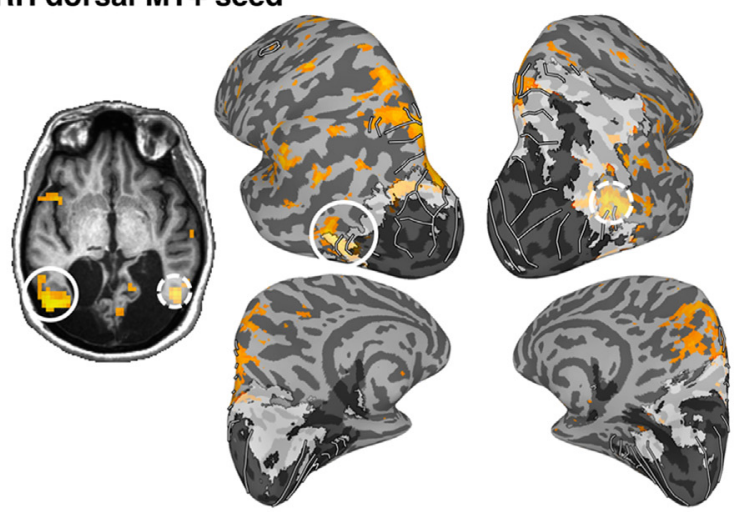

RH ventral MT+ seed

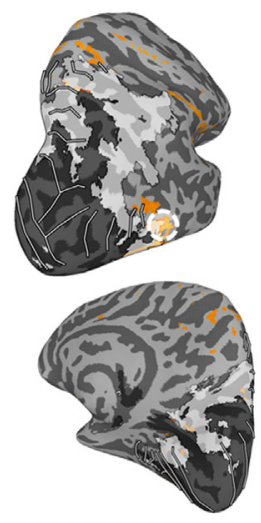

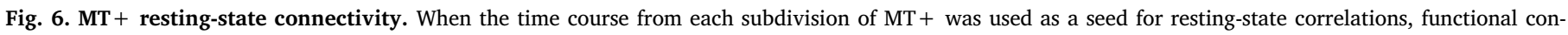

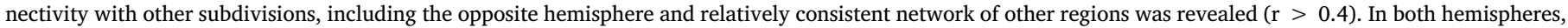

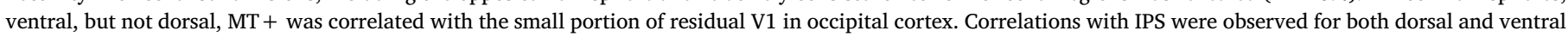

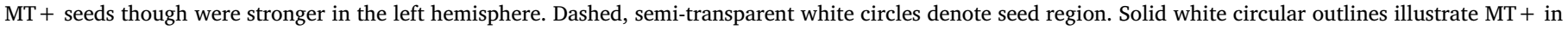
the hemisphere opposite that of the seed. 


\subsubsection{Direction-selective adaptation for random dots}

To assess the degree to which MC's MT + was functional, responses to particular motion directions were assessed using an fMRI adaptation paradigm. fMRI scanning in 2011 confirmed the presence of motionselective activity within MC's MT + bilaterally as well as within the intraparietal sulcus (IPS). Two clusters of activity were again identified within the region of MT+. Activity within both MT + and IPS was modulated by the direction of motion (Fig. 5). An fMRI adaptation paradigm was used to probe the sensitivity of MC's motion-selective areas to particular direction of motion, as had been previously investigated in typical participants (Konen and Kastner, 2008). MC was scanned while viewing blocks of uniform translational (left and down) and flow (outward) and blocks of alternating motion directions (Fig. 5A). In all motion-selective areas, responses to blocks of alternating (i.e. non-adapted) motion were significantly larger than blocks of repeated (adapted) motion (Fig. 5C-D; unpaired t-test; $\mathrm{t}(28)>2.77$; $p<0.01$ ). In contrast, sensitivity to motion stimulation was not detected within occipital or ventral temporal cortex. The remaining tissue in both occipital and ventral temporal cortex in the right hemisphere was visually responsive to full field flickering checkerboard stimuli (Supplementary Figure 4), but neither region showed motion- (vs. static) selective activity nor differential activity between mixed and repeated motion blocks $(\mathrm{t}(28)<0.92 ; p>0.37)$. The profile of motion responses across MC's remaining visual cortex resembles typical activity patterns in healthy individuals where responses to different motion directions, as assessed by motion adaptation, are strongest within MT +, FEF, and parietal cortex and weakest within early visual cortex (Konen and Kastner, 2008; but see Lee and Lee, 2012). Taken together, these data suggest that MC's MT + and motion-sensitive IPS is capable of discriminating motion direction and could support her residual direction discrimination abilities.

\subsubsection{Resting-state functional connectivity}

The functional organization of MT + and MC's remaining visual cortex was further evaluated using functional connectivity analyses on data collected during a long rest scan in the absence of visual stimulation. The activity of MC's motion-sensitive areas was correlated at rest (Fig. 6). When seeding the dorsal and ventral MT + clusters, spatially focal correlations $(\mathrm{r}>0.4 ; \mathrm{t}(227)>6.58 ; p<0.00001)$ were observed with the dorsal MT + ROI in the opposite hemisphere as well as motion-sensitive regions of posterior parietal cortex, including right V3A (Tootell et al., 1997) and IPS0-4 (Konen and Kastner, 2008). Both dorsal and ventral MT + were correlated with anterior occipital cortex.

Using a complementary data-driven ICA (Supplemental Figure 5), other activity networks were identified within and around MT + . One IC map was identified comprising posterior parietal cortex and parts of lateral temporal cortex within and around MT+. The IC map most closely resembled the dorsal attention network (Fox et al., 2005). Another IC map was identified within anterior parietal cortex, anterior lateral temporal cortex, and frontal cortex, and likely overlaps with tool-selective and grasping regions (Culham and Valyear, 2006; Konen et al., 2013). A third IC map was identified within the inferior parietal lobule and the posterior cingulate / precuneus, and most closely resembled the default mode network (Fox et al., 2005). Taken together, these data provide additional support that MC's motion sensitive regions are functionally similar and are distinct from surrounding cortex.
A. RDK Detection

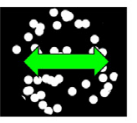

\section{$95 \%$ correct $d^{\prime}=3.48$}

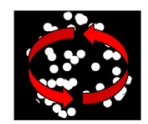

$90 \%$ correct $d^{\prime}=3.52$

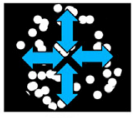

$90 \%$ correct $d^{\prime}=3.19$
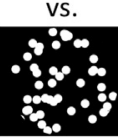

B. RDK Category Discrimination
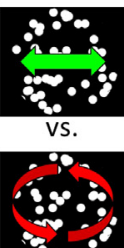
vS.
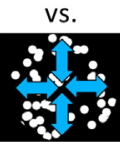

$96 \%$ correct

chance $=33 \%$
C. RDK Opposite Direction Discrimination
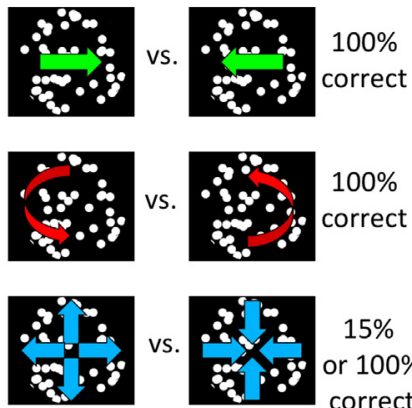

$15 \%$ or $100 \%$ correct
D. Effect of Coherence on RDK Opposite Direction Discrimination

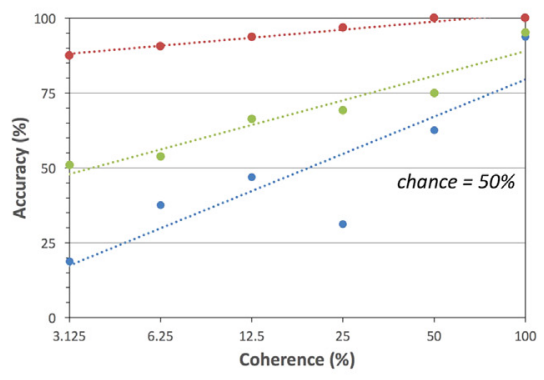

chance $=50 \%$

chance $=50 \%$

E.

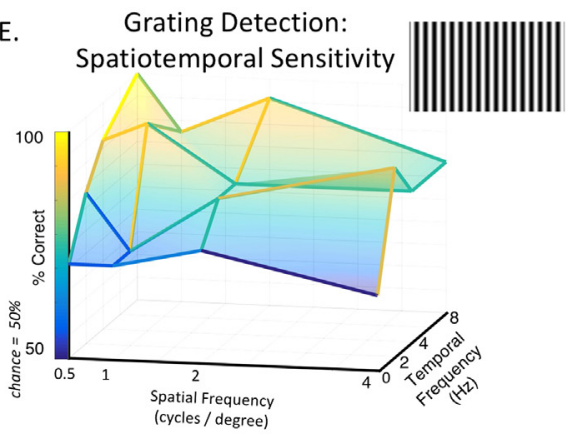

F. Grating Direction Discrimination

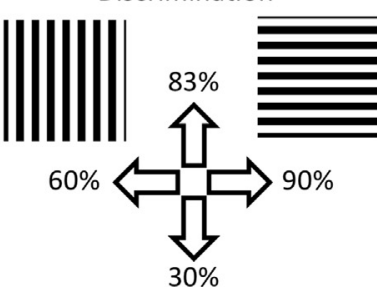

$67 \%$ correct overall (chance $=25 \%$ )
G. Bar Direction Discrimination

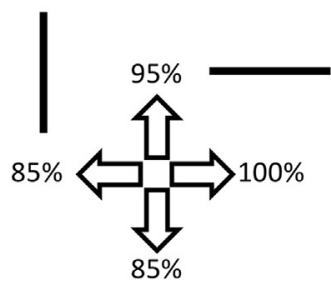

91\% correct overall (chance $=25 \%)$

Fig. 7. Motion psychophysics results. For high-contrast $\left(98 \%+\right.$ contrast) random dot kinematograms (RDKs) with larger-than-typical dot sizes $\left(2.85^{\circ}\right)$, MC showed above-chance performance for (A) motion detection, (B) discrimination of motion translation, rotation and flow and (C) discrimination opposite directions of motion for translation and rotation (with mixed results for flow). (D) Moreover, for all categories of motion, her direction discrimination scaled with motion coherence (though results for flow were noisier). (E) MC was best able to detect gratings at low spatial and high temporal frequencies. MC showed a poorer ability to discriminate motion direction for (F) square-wave gratings than (G) single bar of the grating. 


\subsection{Motion psychophysical testing}

Because MC's lesion mapping and fMRI revealed partial sparing of $\mathrm{MT}+$, the degree of MC's preserved behavioral sensitivity for moving stimuli was tested in a series of psychophysical experiments.

\subsubsection{Random dot kinematograms}

5.2.1.1. Motion detection. As shown in Fig. 7A, for all conditions, MC could discriminate moving from stationary dots with at least $90 \%$ accuracy $(94.7 \%$ across all trials; chance $=50 \%)$. Errors were mostly reports of perceived motion when stationary dots were presented (8.3\%) rather than a failure to perceive motion when moving dots were presented $(2.2 \%)$

5.2.1.2. Motion category discrimination. As shown in Fig. 7B, when MC was shown three categories of motion (translation, rotation or flow), she could discriminate the category with $95.8 \%$ accuracy (where chance was $33 \%$ ).

5.2.1.3. Opposite motion direction discrimination. As shown in Fig. 7C, MC could discriminate between opposite motion directions with $100 \%$ accuracy for translation and rotation. Her performance for flow was more mixed. For the first two blocks of the first session, she performed worse than chance, $15 \%$, even when the experimenter asked her to speak her answers, indicating that she could discern the two directions but not label them correctly. For the last two blocks of the first session and one block in the second session she got $100 \%$ correct.

5.2.1.4. Opposite motion direction discrimination as a function of coherence. As shown in Fig. 7D, for all three motion categories, as motion coherence increased, so did MC's ability to discriminate between opposite directions of motion. Her performance scaled linearly on a log scale. For all categories, her performance was excellent at full coherence (consistent with Fig. 7A). However, at lower levels of coherence, her performance differed across category, with the best performance for rotational and translational motion (with similar performance for left-right and up-down) and poorer and more variable performance for flow. Her performance in flow at low coherence was lower than chance, indicating that as with the $100 \%$ coherence condition in Fig. 7D, her response mapping for flow direction is unreliable.

\subsubsection{Gratings and bars}

5.2.2.1. Gratings: Spatiotemporal sensitivity. Although performance was somewhat variable, as shown in Fig. $7 \mathbf{E}$, there was a clear trend in which MC's performance for detecting gratings was best for combinations of low spatial and high temporal frequencies (e.g., $100 \%$ correct for 0.5 cycles $/{ }^{\circ}$ at $8 \mathrm{~Hz}$ vs. $61 \%$ correct for 4 cycles $/{ }^{\circ}$ at $0 \mathrm{~Hz}$, i.e., stationary).

5.2.2.2. Grating and bar motion. As shown in Fig. 7 F and G, MC's ability to discriminate among four directions of motion was indeed poorer for square-wave gratings (67\%) than for a single bar within the grating (91\%). In particular, MC made many errors for horizontal gratings moving downward, which she often perceived as upward.

\subsubsection{Checkerboards: Contrast response functions}

As in typical observers (Kastner et al., 2004; Schade, 1956; Watson, 2000), MC's contrast response function showed an increase in accuracy as a function of contrast that increased logarithmically when plotted on a linear scale (and thus linearly when plotted on a logarithmic scale, $\mathrm{R}^{2}$ = 0.93; Fig. 8).

\subsection{Data availability}

MC's T1 anatomical volume, lesion mask, and MT localizer have

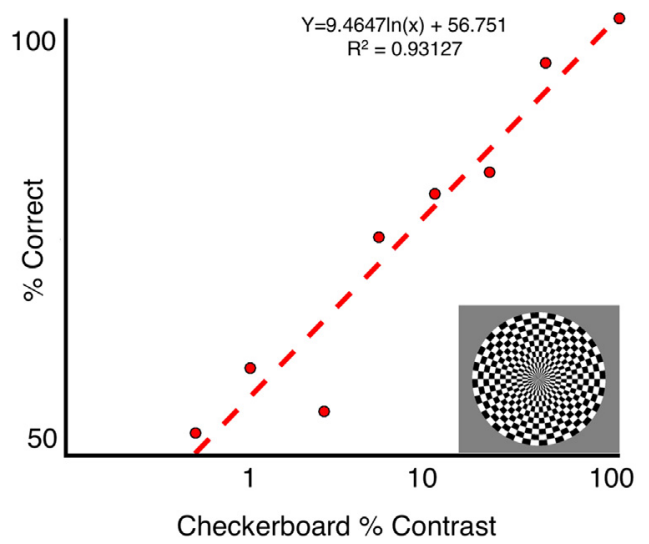

Fig. 8. Psychophysical contrast response functions. In a 2-alternative forced-choice decision, MC's ability to detect a flickering checkerboard increased logarithmically within contrast.

been made publicly available as NIFTI images (Arcaro, 2017).

\section{Discussion}

Our psychophysical and neuroimaging studies of Patient MC provide a detailed characterization of a new case of the scarcely studied Riddoch phenomenon. Most notably, the results show that MC has a rich perceptual experience of motion that is accompanied by robust and reliable activation in visual area MT + even though it abuts her extensive occipitotemporal lesions. Moreover, both her perception of motion and fMRI activation in MT + go beyond a simple response to motion. Behaviorally, she cannot only detect motion but also shows an ability to discriminate motion direction; neurally, she shows a response not just to the presence of motion but also direction-selective adaptation. These results reinforce those highlighting the central role of MT + in motion perception in Riddoch patients (Schoenfeld et al., 2002; Zeki and Ffytche, 1998).

In addition, the careful characterization of MC's case and neuroanatomy provides a foundation for understanding her case in ongoing and future studies. Though Riddoch phenomenon is a striking aspect of MC's case, she also displays other phenomena akin to blindsight and perception-action dissociations (Goodale et al., 2008). These may be related to the particular details of her case, including lesions in the ventral visual stream (which include LO) and a partially spared dorsal visual stream (particularly in the left hemisphere). As with other rare patients such as a DF, a patient with visual form agnosia who shows perception-action dissociations (Goodale and Milner, 1992), the combination of behavioral testing along with structural and functional neuroimaging (Bridge et al., 2013; James et al., 2003) has enabled more sophisticated understanding of behavioral/neural dissociations.

\subsection{What does $M C$ 's case reveal about motion processing in the Riddoch phenomenon?}

MC's case shows that even with considerable damage to a wide swath of early visual areas, rich motion perception can be preserved and utilized for daily functions such as navigation and visually guided actions like catching a ball. We propose that such spared motion perception is enabled by the sparing of processing in the motion-selective complex MT + in humans. MC clearly shows activation at the expected location of MT + based on its sulcal location (Dumoulin et al., 2000), as well as comparisons with probabilistic atlases derived from neurologically intact participants using retinotopic mapping (Wang et al., 2015), cytoarchitectonic divisions (Malikovic et al., 2007), and functional meta-analyses (Yarkoni et al., 2011). Moreover, our resting-state connectivity data suggest that the subdivisions of MT + are interconnected 
with one another and other motion-selective regions. As with other patients with the Riddoch phenomenon and/or blindsight, even with damage to the primary pathway, subcortical pathways may provide input to MT + (Bridge et al., 2008; Leh et al., 2006).

There may also be cases in which MT + activation is found in the absence of the Riddoch phenomenon, that is, without motion awareness (Barleben et al., 2015). Our experiences suggest one possible account for MT + activation in the absence of the Riddoch phenomenon may be a suboptimal choice of stimuli. MC's behavioral detection and discrimination abilities require an optimal combination of low spatial and high temporal frequencies, scale approximately linearly with contrast rather than saturating at low contrasts as expected, and vary widely across stimuli (e.g., better for translation and rotation than flow, better for bars than gratings, and present only for coarse but not fine dot patterns). As such, it seems particularly important for future studies to ensure that a range of stimuli are behaviorally tested and optimized prior to imaging. Another possible account for MT + activation in the absence of motion awareness is that MT + may be necessary but not sufficient for conscious awareness.

MC's data show that residual motion processing in the Riddoch phenomenon goes beyond mere detection of motion but also extends to direction selectivity. Behaviorally, MC was able to discern the direction of dots, bars and gratings substantially better than chance (sometimes with $100 \%$ correct). At the neural level, MT + showed direction-selective adaptation in MC as in past studies of neurologically intact participants (Konen and Kastner, 2008). This finding contradicts the hypothesis that cortically blind patients are able to discriminate direction only for simple stimuli like bars and single dots but not for more complex stimuli like gratings or plaids in their scotomata (Azzopardi and Cowey, 2001). Although we did find that MC performed better at direction discrimination with a single bar than a grating as would have been predicted by Azzopardi \& Cowey, nevertheless, she could discriminate direction better than chance for the grating and almost perfectly for coarse RDKs. These results suggest that at least some patients can discriminate direction when stimuli are optimized for their spatiotemporal sensitivity. The better discrimination for a single bar than a grating may result from differences in motion mechanisms (e.g., easier attentive tracking with a single bar than a crowded grating; Cavanagh, 1992).

\subsection{Potential implications for clinical practice}

Though speculative, MC's case raises the possibility that changes to clinical practice may facilitate recovery in patients with cortical blindness. Such patients tend to be told by the medical profession that visual recovery will not occur, and MC was no exception. However, during the first two years following her brain injury, progressively improving movement perception took place, akin to the cases described by Riddoch (1917), yet her percepts were questioned by clinicians. When she presented two years after her brain injury, she was only conscious of movement, but unaware that this might accord the facility to use vision to guide her movements once more. After being encouraged by her clinician to take advantage of her spared motion perception, MC gained confidence in her newfound abilities and continues to report ongoing improvements. Of course, we cannot exclude the possibility that her behavioral recovery would have happened regardless. Nevertheless, studies have demonstrated that perceptual training for complex movement stimuli can yield improvements in motion perception that generalize to new retinal locations, stimuli and tasks (Cavanaugh et al., 2017; Cavanaugh and Huxlin, 2017; Das et al., 2014; Huxlin et al., 2009; Melnick et al., 2016) MC's case history raises the possibility that even everyday activities may also have the potential to yield everyday benefits with low costs, though empirical validation would be necessary.

\subsection{From where does the input to MT+ arise?}

Our testing thus far has not enabled us to determine the source of input to MT + with certainty. Of course, the most common explanation for residual vision is based on subcortical routes to MT + (including a colliculo-pulvinar route and a koniocellular LGN route). We had hoped to discern the contribution of subcortical inputs from LGN and/or SC via the pulvinar through a variety of methods, including examining contrast response functions, resting-state connectivity, and diffusion tensor imaging (not shown). Though visual responses were observed in MC's LGN and SC, the results from each of these approaches were inconclusive.

A second possibility is that the inputs may be arising from partially preserved tissue in the anterior calcarine cortex, which may correspond to peripheral V1 or perhaps even the prostriata region. MC's spared anterior calcarine tissue may account for her spared motion perimetry in the peripheral upper left quadrant. Activation in this spared region scales with luminance contrast and shows resting-state correlations with MT + However, its responses differed from MT+; specifically, unlike MT + it showed negligible motion selectivity for checkerboards and no evidence of direction-selective adaptation for RDKs (however, even in neurologically intact controls, adaptation is weak in V1, V2 and V3, according to Konen and Kastner, 2008 and unknown in prostriata).

Some have speculated that prostriata may play a role in blindsight and related phenomena (Rockland, 2012) but evidence is scarce. In non-human primates, prostriata is characterized by a strong emphasis on the visual periphery and very short response latencies (Yu et al., 2012). Prostriata has direct connections to peripheral MT (Palmer and Rosa, 2006). Recently, a comparable area has been reported in humans that also lies anterior to V1, represents the far periphery, and responds best to very fast motion (Mikellidou et al., 2017b) and luminance flicker (Dechent and Frahm, 2003). Although MC's prostriata appears anatomically preserved, further testing using functional (Mikellidou et al., 2017b) and anatomical criteria (Glasser et al., 2016, supplemental neuroanatomical results) would be needed to distinguish it from anterior visual cortex.

In total, MC's spared anterior calcarine, which represents the visual periphery and may correspond to anterior V1 or prostriata, may play a role in her awareness of motion and spared MT + activation. However, we must emphasize that it certainly does not enable "normal" processing. Most strikingly, MC's peripheral vision does not enable many other visual functions such as awareness of static targets or good form recognition.

\subsection{Caveats of MC's case and single case studies}

There are numerous caveats to MC's case; however, with careful consideration these should not detract from the value of her case.

We must emphasize that we are not claiming that MC's perception or activation fall within the range of normal controls. Any comparisons with controls are indirect, based on the fact that MT + is one of the most robust and reliable visual areas to find in individuals (Tootell et al., 1995; Watson et al., 1993) and many of the experiments were motivated by previous effects in controls (e.g., Kastner et al., 2004; Konen and Kastner, 2008). To make any claims of normal functionality, we would need to test a reasonably sized sample of control participants (ideally age- and sex-matched) on our task and determine whether MC fell within or outside the expected norms. However, we are not making such claims, only emphasizing that MC shows robust motion activation that was very replicable across stimuli, paradigms, and even scanners over six years and that on a single-subject level, she shows statistically significant direction discrimination.

Another caveat to MC's case is that in the absence of foveal cortex (and the presence of strabismus), eye tracking calibration and testing was not straightforward. Thus, it is quite possible, even likely, that MC was moving her eyes during testing. However, we must emphasize that 
regardless of whether her motion detection and discrimination abilities are due to stimulus motion, retinal motion from eye movements, or some combination, she retains those abilities. Without the ability to assess calibrated fixation, our attempts to examine perception and activation at different retinotopic locations were not successful. Nevertheless, the assessment of her structural data with respect to a normative atlas, provides some clues as to the sparing of early retinotopic cortex.

\section{5. $M C^{\prime}$ 's case in the bigger picture}

Given the paucity and idiosyncrasies of patients with the Riddoch phenomenon, MC's case provides a valuable addition to the literature that can serve as an example and foundation for ongoing and future studies.

MC's case bears striking similarities to another patient, TN (de Gelder et al., 2008). TN, like MC, had multiple strokes that led to extensive bilateral lesions in early visual cortex and many spared abilities, including locomotion and navigation. The degree to which TN displays the Riddoch phenomenon is unclear. Perimetry for static and flickering targets revealed no spared vision (though moving targets do not appear to have been tested); however, TN "sporadically claims to 'feel' the occurrence of visual movement" and shows spared MT + activation for looming dots (compared to receding or rotating motion or static dots) (Hervais-Adelman et al., 2015). Despite his considerable visual impairment, TN can discriminate positive and negative facial expressions, and his amygdala exhibits increased activity when viewing faces with emotional expressions (Burra et al., 2017; Pegna et al., 2005). Interestingly, MC has also been shown to discriminate facial emotions better than chance even though she could not discriminate facial gender (Striemer et al., 2017). Patients MC and TN also share functional similarities with another patient, BI, who also has bilateral occipital damage (which in his case arose in early development), and shows spared navigational abilities and affective processing (Mundinano et al., 2017).

The registration and comparison of MC's structural anatomy with an atlas of visual areas based on control participants will facilitate the interpretation of behavioral and neuroimaging phenomena. Already, we have shown that, despite damage to an area putatively important for both tactile and visual shape processing (LOtv subdivision of the lateral occipital complex; Amedi et al., 2001), MC shows preserved tactile shape processing (Snow et al., 2015). The new structural imaging analyses help clarify exactly which divisions of lateral occipital cortex are implicated. Preliminary testing and analysis also suggests that MC shows a dissociation between visual perception and visually guided actions (Goodale et al., 2008) and her case is likely to provide a valuable additional case of this rare dissociation (Goodale and Milner, 1992; Karnath et al., 2009).

\subsection{Conclusion}

Here we described a neuropsychological case characterized by a combination of psychophysical testing and structural MRI, and taskbased and resting-state functional MRI. With many criteria considered in combination, MC's case supports a key role for the MT + motion complex in the Riddoch phenomenon, including key features such as direction selectivity, even for complex stimuli such as gratings or plaids.

\section{Acknowledgements}

This work was supported by a Discovery Grant from the Natural Sciences and Engineering Research Council of Canada (RGPIN-201604748) and an Operating Grant from the Canadian Institutes of Health Research to JCC, and by grants from the National Institutes of Health (RO1MH064043 and RO1EY017699) and the National Science Foundation (BCS1025149 and BCS1328270) to SK. We thank Lucia van
Eimeren and Kevin Stubbs for assistance with data collection and analysis and an anonymous reviewer for drawing our attention to the possible role of area prostriata in MC's case.

\section{Appendix A. Supplementary material}

Supplementary data associated with this article can be found in the online version at http://dx.doi.org/10.1016/j.neuropsychologia.2018. 05.008 .

\section{References}

Ajina, S., Bridge, H., 2016. Blindsight and unconscious vision: what they teach us about the human visual system. Neuroscientist. http://dx.doi.org/10.1177/ 1073858416673817.

Ajina, S., Bridge, H., 2018. Subcortical pathways to extrastriate visual cortex underlie residual vision following bilateral damage to V1. Neuropsychologia. http://dx.doi. org/10.1016/j.neuropsychologia.2018.01.007.

Ajina, S., Kennard, C., Rees, G., Bridge, H., 2015a. Motion area V5/MT + response to global motion in the absence of V1 resembles early visual cortex. Brain 138 (1), 164-178. http://dx.doi.org/10.1093/brain/awu328.

Ajina, S., Pestilli, F., Rokem, A., Kennard, C., Bridge, H., 2015b. Human blindsight is mediated by an intact geniculo-extrastriate pathway. ELife 4, 1-23. http://dx.doi. org/10.7554/eLife.08935.

Amano, K., Wandell, B.A., Dumoulin, S.O., 2009. Visual field maps, population receptive field sizes, and visual field coverage in the human MT + complex. J. Neurophysiol. 102 (5), 2704-2718. http://dx.doi.org/10.1152/jn.00102.2009.

Amedi, A., Malach, R., Hendler, T., Peled, S., Zohary, E., 2001. Visuo-haptic object-related activation in the ventral visual pathway. Nat. Neurosci. 4 (3), 324-330. http:// dx.doi.org/10.1038/85201.

Arcaro, M., 2017. MC T1 anatomical. Harv. Dataverse. http://dx.doi.org/10.7910/DVN/ OEFOEI.

Arcaro, M.J., Pinsk, M.A., Kastner, S., 2015. The anatomical and functional organization of the human visual pulvinar. J. Neurosci. 35 (27), 9848-9871. http://dx.doi.org/10 1523/JNEUROSCI.1575-14.2015.

Arnott, S.R., Cant, J.S., Dutton, G.N., Goodale, M.A., 2008. Crinkling and crumpling: an auditory fMRI study of material properties. NeuroImage 43 (2), 368-378. http://dx. doi.org/10.1016/j.neuroimage.2008.07.033.

Azzopardi, P., Cowey, A., 2001. Motion discrimination in cortically blind patients. Brain 124 (1), 30-46. http://dx.doi.org/10.1093/brain/124.1.30.

Azzopardi, P., Hock, H.S., 2011. Illusory motion perception in blindsight. Proc. Natl. Acad. Sci. USA 108 (2), 876-881. http://dx.doi.org/10.1073/pnas.1005974108.

Barleben, M., Stoppel, C.M., Kaufmann, J., Merkel, C., Wecke, T., Goertler, M., Schoenfeld, M.A., 2015. Neural correlates of visual motion processing without awareness in patients with striate cortex and pulvinar lesions. Hum. Brain Mapp. 36 (4), 1585-1594. http://dx.doi.org/10.1002/hbm.22725.

Barton, J.J.S., Sharpe, J.A., 1997. Motion direction discrimination in blind hemifields Ann. Neurol. 41 (2), 255-264. http://dx.doi.org/10.1002/ana.410410217.

Berman, R.A., Wurtz, R.H., 2010. Functional identification of a pulvinar path from superior colliculus to cortical area MT. J. Neurosci. 30 (18), 6342-6354. http://dx.doi. org/10.1523/JNEUROSCI.6176-09.2010.

Bridge, H., Thomas, O., Jbabdi, S., Cowey, A., 2008. Changes in connectivity after visual cortical brain damage underlie altered visual function. Brain 131 (6), 1433-1444. http://dx.doi.org/10.1093/brain/awn063.

Bridge, H., Thomas, O.M., Minini, L., Cavina-Pratesi, C., Milner, A.D., Parker, A.J., 2013 Structural and functional changes across the visual cortex of a patient with visual form agnosia. J. Neurosci. 33 (31), 12779-12791. http://dx.doi.org/10.1523/ JNEUROSCI.4853-12.2013.

Burra, N., Hervais-Adelman, A., Celeghin, A., de Gelder, B., Pegna, A.J., 2017. Affective blindsight relies on low spatial frequencies. Neuropsychologia. http://dx.doi.org/10. 1016/j.neuropsychologia.2017.10.009.

Cavanagh, P., 1992. Attention-based motion perception. Science 257 (5076), 1563-1565 (Retrieved from). 〈http://www.ncbi.nlm.nih.gov/pubmed/1523411〉.

Cavanaugh, M.R., Barbot, A., Carrasco, M., Huxlin, K.R., 2017. Feature-based attention potentiates recovery of fine direction discrimination in cortically blind patients. Neuropsychologia. http://dx.doi.org/10.1016/j.neuropsychologia.2017.12.010.

Cavanaugh, M.R., Huxlin, K.R., 2017. Visual discrimination training improves Humphrey perimetry in chronic cortically induced blindness. Neurology 88 (19), 1856-1864. http://dx.doi.org/10.1212/WNL.0000000000003921.

Cohen, L.G., Celnik, P., Pascual-leone, A., Corwell, B., Faiz, L., Hallett, M., Catala, M.D., 1997. Functional relevance of cross-modal plasticity in blind humans. Nature 389, 5-8.

Collins, C.E., Lyon, D.C., Kaas, J.H., 2005. Distribution across cortical areas of neurons projecting to the superior colliculus in new world monkeys. Anat. Rec. Part A Discov. Mol. Cell. Evolut. Biol. 285 (1), 619-627. http://dx.doi.org/10.1002/ar.a.20207.

Culham, J.C., Valyear, K.F., 2006. Human parietal cortex in action. Curr. Opin. Neurobiol. 16 (2), 205-212. http://dx.doi.org/10.1016/j.conb.2006.03.005.

Danckert, J., Culham, J.C., 2010. Reflections on blindsight: neuroimaging and behavioural explorations clarify a case of reversed localisation in the blind field of a patient with hemianopia. Can. J. Exp. Psychol. 64 (2), 86-101. http://dx.doi.org/10. 1037/a0017426.

Das, A., Tadin, D., Huxlin, K.R., 2014. Beyond blindsight: properties of visual relearning 
in cortically blind fields. J. Neurosci. 34 (35), 11652-11664. http://dx.doi.org/10. 1523/JNEUROSCI.1076-14.2014.

de Gelder, B., Tamietto, M., van Boxtel, G., Goebel, R., Sahraie, A., van den Stock, J., Pegna, A., 2008. Intact navigation skills after bilateral loss of striate cortex. Curr. Biol. 18 (24). http://dx.doi.org/10.1016/j.cub.2008.11.002.

Dechent, P., Frahm, J., 2003. Characterization of the human visual V6 complex by functional magnetic resonance imaging. Eur. J. Neurosci. 17 (10), 2201-2211. http://dx.doi.org/10.1046/j.1460-9568.2003.02645.x.

Dukelow, S.P., DeSouza, J.F., Culham, J.C., van den Berg, A.V., Menon, R.S., Vilis, T., 2001. Distinguishing subregions of the human MT + complex using visual fields and pursuit eye movements. J. Neurophysiol. 86 (4), 1991-2000. (Retrieved from) $\langle$ http://www.ncbi.nlm.nih.gov/pubmed/11600656〉.

Dumoulin, S.O., Bittar, R.G., Kabani, N.J., Baker, C.L., Le Goualher, G., Pike, G.B., Evans, A.C., 2000. A new anatomical landmark for reliable identification of human area V5/ MT: a quantitative analysis of sulcal patterning. Cereb. Cortex 10 (5), 454-463. (Retrieved from). 〈http://www.ncbi.nlm.nih.gov/pubmed/10847595〉.

Dutton, G.N., 2003. Cognitive vision, its disorders and differential diagnosis in adults and children: knowing where and what things are. Eye 17 (3), 289-304. http://dx.doi. org/10.1038/sj.eye.6700344/r6700344. (pii)

Fendrich, R., Wessinger, C.M., Gazzaniga, M.S., 1992. Residual vision in a scotoma: implications for blindsight. Science 258 (5087), 1489-1491. (Retrieved from). 〈http:// www.ncbi.nlm.nih.gov/pubmed/1439839>.

Fox, M.D., Snyder, A.Z., Vincent, J.L., Corbetta, M., Van Essen, D.C., Raichle, M.E., 2005. The human brain is intrinsically organized into dynamic, anticorrelated functional networks. Proc. Natl. Acad. Sci. USA 102 (27), 9673-9678. http://dx.doi.org/10 1073/pnas.0504136102.

Glasser, M.F., Coalson, T.S., Robinson, E.C., Hacker, C.D., Harwell, J., Yacoub, E., Van Essen, D.C., 2016. A multi-modal parcellation of human cerebral cortex. Nature 536 (7615), 171-178. http://dx.doi.org/10.1038/nature18933.

Goodale, M.A., Milner, A.D., 1992. Separate visual pathways for perception and action. Trends Neurosci. 15 (1), 20-25. (Retrieved from). 〈http://www.ncbi.nlm.nih.gov/ pubmed/1374953>.

Goodale, M.A., Wolf, M.E., Whitwell, R.L., Brown, L.E., Cant, J.S., Chapman, C.S., Dutton, G.N., 2008. Preserved motion processing and visuomotor control in a patient with large bilateral lesions of occipitotemporal cortex. J. Vision. 8, 371. http://dx.doi.org/ $10.1167 / 8.6 .371$

Grill-Spector, K., Kushnir, T., Edelman, S., Avidan, G., Itzchak, Y., Malach, R., 1999. Differential processing of objects under various viewing conditions in the human lateral occipital complex. Neuron 24 (1), 187-203. (Retrieved from). 〈http://www. ncbi.nlm.nih.gov/pubmed/10677037>.

Hervais-Adelman, A., Legrand, L.B., Zhan, M., Tamietto, M., de Gelder, B., Pegna, A.J. 2015. Looming sensitive cortical regions without V1 input: evidence from a patien with bilateral cortical blindness. Front. Integr. Neurosci. 9, 1-12. http://dx.doi.org/ 10.3389/fnint.2015.00051

Hudson, C., Wild, J.M., 1992. Assessment of physiologic statokinetic dissociation by automated perimetry. Invest. Ophthalmol. Vis. Sci. 33 (11), 3162-3168. (Retrieved from). 〈http://www.ncbi.nlm.nih.gov/pubmed/1399422〉.

Huk, A.C., Dougherty, R.F., Heeger, D.J., 2002. Retinotopy and functional subdivision of human areas MT and MST. J. Neurosci. 22 (16), 7195-7205 (https://doi.org/ 20026661)

Humphrey, N.K., 1974. Vision in a monkey without striate cortex: a case study. Perception 3 (3), 241-255

Huxlin, K.R., Martin, T., Kelly, K., Riley, M., Friedman, D.I., Burgin, W.S., Hayhoe, M., 2009. Perceptual relearning of complex visual motion after V1 damage in humans. J. Neurosci. 29 (13), 3981-3991. http://dx.doi.org/10.1523/JNEUROSCI.4882-08. 2009.

James, T.W.T.W., Culham, J.C., Humphrey, G.K.K., Milner, A.D.D., Goodale, M.A.M.A., 2003. Ventral occipital lesions impair object recognition but not object-directed grasping: an fMRI study. Brain 126 (Pt 11), 2463-2475. http://dx.doi.org/10.1093/ brain/awg248.

Karnath, H.-O., Ruter, J., Mandler, A., Himmelbach, M., 2009. The anatomy of object recognition-visual form agnosia caused by medial occipitotemporal stroke. J. Neurosci. 29 (18), 5854-5862. http://dx.doi.org/10.1523/JNEUROSCI.5192-08. 2009.

Kastner, S., O'Connor, D.H., Fukui, M.M., Fehd, H.M., Herwig, U., Pinsk, M.A., 2004 Functional imaging of the human lateral geniculate nucleus and pulvinar. J. Neurophysiol. 91 (1), 438-448. http://dx.doi.org/10.1152/jn.00553.2003.

Kentridge, R.W., Heywood, C.A., 1999. The status of blindsight. J. Conscious. Stud. 6 (5), 3-11.

Kentridge, R.W., Heywood, C.A., Weiskrantz, L., 1997. Residual vision in multiple retinal locations within a scotoma: implications for blindsight. J. Cogn. Neurosci. 9 (2), 191-202. http://dx.doi.org/10.1162/jocn.1997.9.2.191.

Konen, C.S., Kastner, S., 2008. Representation of eye movements and stimulus motion in topographically organized areas of human posterior parietal cortex. J. Neurosci. 28 (33), 8361-8375. http://dx.doi.org/10.1523/JNEUROSCI.1930-08.2008.

Konen, C.S., Mruczek, R.E.B., Montora, J.L., Kastner, S., 2013. Functional organization of human posterior parietal cortex: grasping- and reaching-related activations relative to topographically organized cortex. J. Neurophysiol. 2897-2908. http://dx.doi.org/ 10.1152/jn.00657.2012.

Krauth, A., Blanc, R., Poveda, A., Jeanmonod, D., Morel, A., Székely, G., 2010. A mean three-dimensional atlas of the human thalamus: generation from multiple histological data. NeuroImage 49 (3), 2053-2062. http://dx.doi.org/10.1016/j.neuroimage. 2009.10.042.

Lee, H.A., Lee, S.-H., 2012. Hierarchy of direction-tuned motion adaptation in human visual cortex. J. Neurophysiol. 107 (8), 2163-2184. http://dx.doi.org/10.1152/jn. 00923.2010.
Leh, S.E., Johansen-Berg, H., Ptito, A., 2006. Unconscious vision: new insights into the neuronal correlate of blindsight using diffusion tractography. Brain 129 (7), 1822-1832. http://dx.doi.org/10.1093/brain/awl111.

Malikovic, A., Amunts, K., Schleicher, A., Mohlberg, H., Eickhoff, S.B., Wilms, M., Zilles, K., 2007. Cytoarchitectonic analysis of the human extrastriate cortex in the region of V5/MT + : a probabilistic, stereotaxic map of area hOc5. Cereb. Cortex 17 (3), 562-574. http://dx.doi.org/10.1093/cercor/bhj181.

Melnick, M.D., Tadin, D., Huxlin, K.R., 2016. Relearning to see in cortical blindness. Neuroscientist 22 (2), 199-212. http://dx.doi.org/10.1177/1073858415621035.

Mikellidou, K., Arrighi, R., Aghakhanyan, G., Tinelli, F., Frijia, F., Crespi, S., Morrone M.C., 2017a. Plasticity of the human visual brain after an early cortical lesion. Neuropsychologia 0-1. http://dx.doi.org/10.1016/j.neuropsychologia.2017.10.033.

Mikellidou, K., Kurzawski, J.W., Frijia, F., Montanaro, D., Greco, V., Burr, D.C., Morrone M.C., 2017b. Area prostriata in the human brain. Curr. Biol. 27 (19), 3056-3060. http://dx.doi.org/10.1016/j.cub.2017.08.065.

Milner, A.D., Goodale, M.A., 1995. The Visual Brain in Action. Oxford University Press, Oxford, U.K.

Morel, A., Magnin, M., Jeanmonod, D., 1997. Multiarchitectonic and stereotactic atlas of the human thalamus. J. Comp. Neurol. 387 (4), 588-630. (Retrieved from). 〈http:// www.ncbi.nlm.nih.gov/pubmed/9373015>.

Mundinano, I.-C., Chen, J., de Souza, M., Sarossy, M.G., Joanisse, M.F., Goodale, M.A., Bourne, J.A., 2017. More than blindsight: case report of a child with extraordinary visual capacity following perinatal bilateral occipital lobe injury. Neuropsychologia. http://dx.doi.org/10.1016/j.neuropsychologia.2017.11.017.

Palmer, S.M., Rosa, M.G.P., 2006. A distinct anatomical network of cortical areas for analysis of motion in far peripheral vision. Eur. J. Neurosci. 24 (8), 2389-2405. http://dx.doi.org/10.1111/j.1460-9568.2006.05113.x.

Pegna, A.J., Khateb, A., Lazeyras, F., Seghier, M.L., 2005. Discriminating emotional faces without primary visual cortices involves the right amygdala. Nat. Neurosci. 8 (1), 24-25. http://dx.doi.org/10.1038/nn1364.

Phu, J., Al-Saleem, N., Kalloniatis, M., Khuu, S.K., 2016. Physiologic statokinetic dissociation is eliminated by equating static and kinetic perimetry testing procedures. J. Vision. 16 (14), 5. http://dx.doi.org/10.1167/16.14.5.

Pitzalis, S., Galletti, C., Huang, R.-S., Patria, F., Committeri, G., Galati, G., Sereno, M.I., 2006. Wide-field retinotopy defines human cortical visual area V6. J. Neurosci. 26 (30), 7962-7973. http://dx.doi.org/10.1523/JNEUROSCI.0178-06.2006.

Pitzalis, S., Sereno, M.I., Committeri, G., Fattori, P., Galati, G., Tosoni, a., Galletti, C., 2013. The human homologue of macaque area V6A. NeuroImage 82, 517-530. http://dx.doi.org/10.1016/j.neuroimage.2013.06.026.

Radoeva, P.D., Prasad, S., Brainard, D.H., Aguirre, G.K., 2008. Neural activity within area V1 reflects unconscious visual performance in a case of blindsight. J. Cogn. Neurosci. 20 (11), 1927-1939. http://dx.doi.org/10.1162/jocn.2008.20139.Neural.

Riddoch, G., 1917. Dissociation of visual perceptions due to occipital injuries, with especial reference to appreciation of movement. Brain 40, 15-57.

Rockland, K.S., 2012. Visual system: prostriata-a visual area off the beaten path. Curr Biol. 22 (14), R571-R573. http://dx.doi.org/10.1016/j.cub.2012.05.030.

Rodman, H.R., Gross, C.G., Albright, T.D., 1990. Afferent basis of visual response properties in area MT of the macaque. II. Effects of superior colliculus removal. J. Neurosci. 10 (4), 1154-1164. (Retrieved from). 〈http://www.ncbi.nlm.nih.gov/ pubmed/2329373>.

Safran, A.B., Glaser, J.S., 1980. Statokinetic dissociation in lesions of the anterior visual pathways. A reappraisal of the Riddoch phenomenon. Arch. Ophthalmol. 98 (2) 291-295. http://dx.doi.org/10.1001/archopht.1980.01020030287009.

Schade, O.H., 1956. Optical and photoelectric analog of the eye. J. Opt. Soc. Am. 46 (9), 721-739. (Retrieved from). 〈http://www.ncbi.nlm.nih.gov/pubmed/13358013〉.

Schmid, M.C., Mrowka, S.W., Turchi, J., Saunders, R.C., Wilke, M., Peters, A.J., Leopold, D.A., 2010. Blindsight depends on the lateral geniculate nucleus. Nature 466 (7304), 373-377. http://dx.doi.org/10.1038/nature09179.

Schmid, M.C., Schmiedt, J.T., Peters, A.J., Saunders, R.C., Maier, A., Leopold, D.A., 2013 Motion-sensitive responses in visual area V4 in the absence of primary visual cortex. J. Neurosci. 33 (48), 18740-18745. http://dx.doi.org/10.1523/JNEUROSCI.392313.2013.

Schoenfeld, M.A., Noesselt, T., Poggel, D., Tempelmann, C., Hopf, J.M., Woldorff, M.G., Hillyard, S.A., 2002. Analysis of pathways mediating preserved vision after striate cortex lesions. Ann. Neurol. 52 (6), 814-824. http://dx.doi.org/10.1002/ana.10394.

Snow, J.C., Goodale, M.A., Culham, J.C., 2015. Preserved Haptic Shape Processing after Bilateral LOC Lesions. J. Neurosci. 35 (40), 13745-13760. http://dx.doi.org/10. 1523/JNEUROSCI.0859-14.2015.

Stoerig, P., Kleinschmidt, A., Frahm, J., 1998. No visual responses in denervated V1: highresolution functional magnetic resonance imaging of a blindsight patient. Neuroreport 9 (1), 21-25. http://dx.doi.org/10.1097/00001756-199801050-00005.

Striemer, C.L., Whitwell, R.L., Goodale, M.A., 2017. Affective blindsight in the absence of input from face processing regions in occipital-temporal cortex. Neuropsychologia 1-8. http://dx.doi.org/10.1016/j.neuropsychologia.2017.11.014.

Thaler, L., Paciocco, J., Daley, M., Lesniak, G.D.G.D., Purcell, D.W.D.W., Fraser, J.A.A., Culham, J.C.J.C., 2016. A selective impairment of perception of sound motion direction in peripheral space: a case study. Neuropsychologia 80, 79-89. http://dx.doi. org/10.1016/j.neuropsychologia.2015.11.008.

Tootell, R.B.H., Mendola, J.D., Hadjikhani, N.K., Ledden, P.J., Liu, A.K., Reppas, J.B., Dale, A.M., 1997. Functional analysis of V3A and related areas in human visual cortex. J. Neurosci. 17 (18), 7060-7078. (Retrieved from). 〈http://www.ncbi.nlm. nih.gov/pubmed/9278542>.

Tootell, R.B.H., Reppas, J.B., Kwong, K.K., Malach, R., Born, R.T., Brady, T.J., Belliveau, J.W., 1995. Functional analysis of human MT and related visual cortical areas using magnetic resonance imaging. J. Neurosci. 15 (4), 3215-3230. (Retrieved from) $\langle$ http://www.ncbi.nlm.nih.gov/pubmed/7722658〉. 
Wang, L., Mruczek, R.E.B., Arcaro, M.J., Kastner, S., 2015. Probabilistic maps of visual topography in human cortex. Cereb. Cortex 25 (10), 3911-3931. http://dx.doi.org/ 10.1093/cercor/bhu277.

Warner, C.E., Kwan, W.C., Wright, D., Johnston, L.A., Egan, G.F., Bourne, J.A., 2015 Preservation of vision by the pulvinar following early-life primary visual cortex lesions. Curr. Biol. 25 (4), 424-434. http://dx.doi.org/10.1016/j.cub.2014.12.028.

Watson, A.B., 2000. Visual detection of spatial contrast patterns: evaluation of five simple models. Opt. Express 6 (1), 12-33. (Retrieved from). 〈http://www.ncbi.nlm.nih. gov/pubmed/12238521>.

Watson, J.D., Myers, R., Frackowiak, R.S., Hajnal, J.V., Woods, R.P., Mazziotta, J.C., Zeki, S., 1993. Area V5 of the human brain: evidence from a combined study using positron emission tomography and magnetic resonance imaging. Cereb. Cortex 3 (2), 79-94. (Retrieved from). 〈http://www.ncbi.nlm.nih.gov/pubmed/8490322〉.

Weiskrantz, L., Warrington, E.K., Sanders, M.D., Marshall, J., 1974. Visual capacity in the hemianopic field following a restricted occipital ablation. Brain 97 (4), 709-728. (Retrieved from). 〈http://www.ncbi.nlm.nih.gov/pubmed/4434190〉.

Yarkoni, T., Poldrack, R.A., Nichols, T.E., Van Essen, D.C., Wager, T.D., 2011. Large-scale automated synthesis of human functional neuroimaging data. Nat. Methods 8 (8), 665-670. http://dx.doi.org/10.1038/nmeth.1635.
Yu, H., Chaplin, T.A., Davies, A.J., Verma, R., Rosa, M.G.P., 2012. A specialized area in limbic cortex for fast analysis of peripheral vision. Curr. Biol. 22 (14), 1351-1357. http://dx.doi.org/10.1016/j.cub.2012.05.029.

Zappia, R.J., Enoch, J.M., Stamper, R., Winkelman, J.Z., Gay, A.J., 1971. The Riddoch phenomenon revealed in non-occipital lobe lesions. Br. J. Ophthalmol. 55 (6), 416-420. http://dx.doi.org/10.1136/bjo.55.6.416.

Zeki, S., Ffytche, D.H., 1998. The Riddoch syndrome: insights into the neurobiology of conscious vision. Brain 121 (1), 25-45. http://dx.doi.org/10.1093/brain/121.1.25.

Zeki, S., Watson, J.D., Lueck, C.J., Friston, K.J., Kennard, C., Frackowiak, R.S., 1991. A direct demonstration of functional specialization in human visual cortex. J. Neurosci. 11 (3), 641-649. (Retrieved from). 〈http://www.ncbi.nlm.nih.gov/pubmed/ 2002358>.

Zihl, J., von Cramon, D., Mai, N., 1983. Selective disturbance of movement vision after bilateral brain damage. Brain 106 (Pt 2), 313-340. (Retrieved from). 〈http://www. ncbi.nlm.nih.gov/pubmed/6850272>.

Zihl, J., von Cramon, D., Mai, N., Schmid, C., 1991. Disturbance of movement vision afte bilateral posterior brain damage. Further evidence and follow up observations. Brain 114 (Pt 5), 2235-2252. (Retrieved from). 〈http://www.ncbi.nlm.nih.gov/pubmed/ 1933243>. 